DIW BERLIN

Discussion

Papers
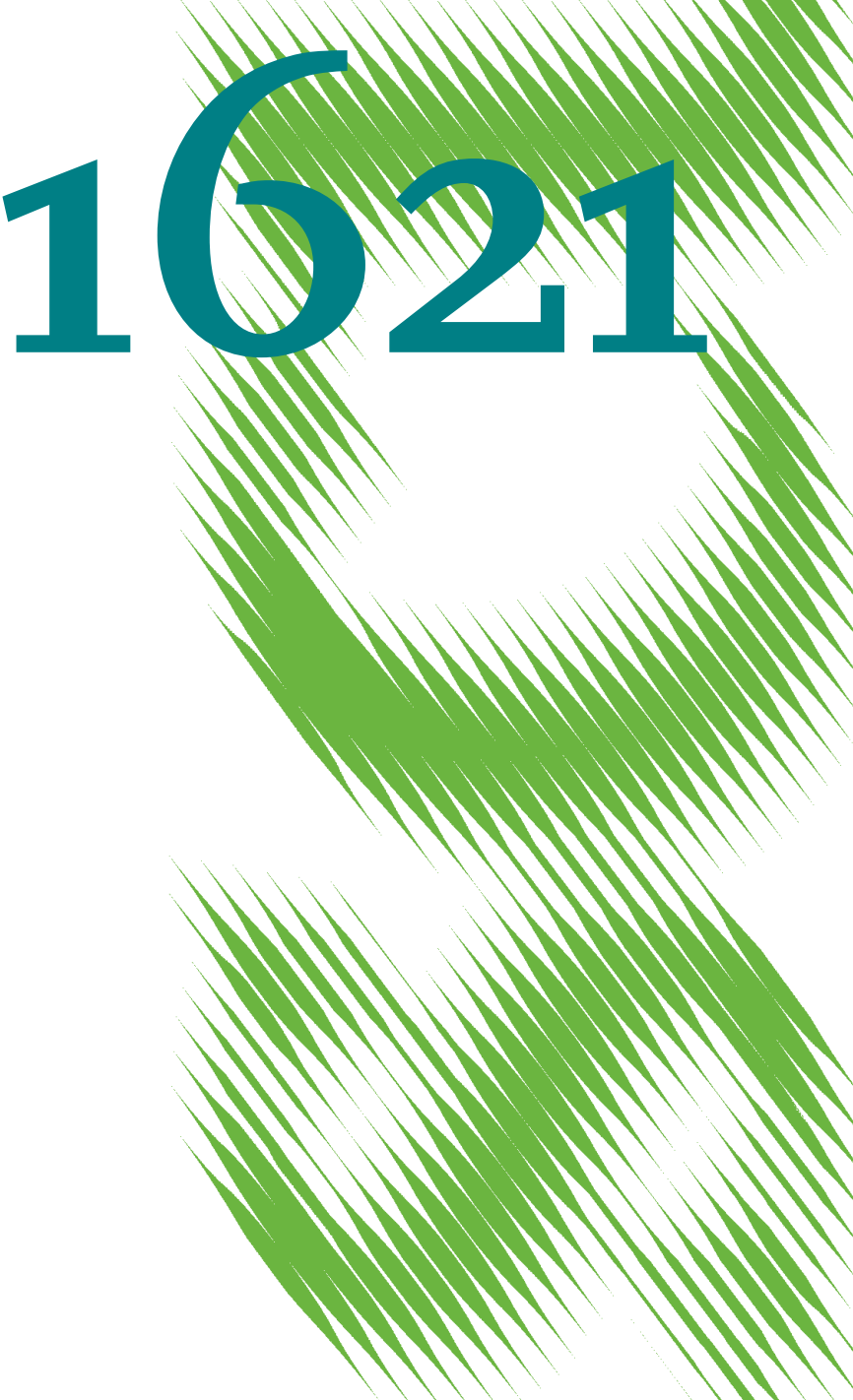

MIMIMIMIMIIIT

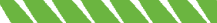

Do Benefits from Dynamic Tariffing Rise?

Welfare Effects of Real-Time Pricing

under Carbon-Tax-Induced Variable

Renewable Energy Supply 
Opinions expressed in this paper are those of the author(s) and do not necessarily reflect views of the institute.

IMPRESSUM

(C) DIW Berlin, 2016

DIW Berlin

German Institute for Economic Research

Mohrenstr. 58

10117 Berlin

Tel. +49 (30) $89789-0$

Fax +49 (30) $89789-200$

http://www.diw.de

ISSN electronic edition 1619-4535

Papers can be downloaded free of charge from the DIW Berlin website:

http://www.diw.de/discussionpapers

Discussion Papers of DIW Berlin are indexed in RePEc and SSRN:

http://ideas.repec.org/s/diw/diwwpp.html

http://www.ssrn.com/link/DIW-Berlin-German-Inst-Econ-Res.html 


\title{
Do Benefits From Dynamic Tariffing Rise? Welfare Effects of Real-Time Pricing Under Carbon-Tax-Induced Variable Renewable Energy Supply
}

\author{
Christian Gambardella ${ }^{\mathrm{a}, *}$, Michael Pahle ${ }^{\mathrm{a}}$, Wolf-Peter Schill ${ }^{\mathrm{b}}$ \\ ${ }^{a}$ Potsdam Institute for Climate Impact Research, P.O. Box 601203, 14412 Potsdam, Germany \\ ${ }^{b}$ German Institute for Economic Research (DIW Berlin), Mohrenstr. 58, 10117 Berlin, Germany
}

\begin{abstract}
Common intuition holds that retail real-time pricing (RTP) of electricity demand should become more beneficial in markets with high variable renewable energy (VRE) supply mainly due to increased price volatility. Using German market data, we test this intuition by simulating long-run electricity market equilibria with carbon-tax-induced VRE investment and real-time price responsive and nonresponsive consumption behavior. We find that the potential welfare gains from RTP are only partially explained by price volatility and are rather driven by opposing wholesale price effects caused by the technology portfolio changes from carbon taxation. Consequently, annual benefits from RTP actually change nonmonotonously with the carbon tax level, implying that increasing RTP at relatively high VRE shares can be both less and much more beneficial than without VRE supply. Nonetheless, as zero marginal cost supply becomes abundant with VRE entry, allocative efficiency increasingly depends on exposing more and more consumers to RTP.
\end{abstract}

Keywords: Real-time pricing; Electricity; Variable renewables; Carbon taxation; Welfare analysis; Partial equilibrium modeling

\section{Introduction}

Electricity consumers over- or underconsume most of the time, since they usually face time-invariant retail prices despite time-variant wholesale prices. Hence, introducing realtime retail pricing (RTP) to incentivize higher consumption when energy is relatively cheap and lower consumption when it is relatively expensive improves allocative efficiency of electricity markets in the short and long run (Borenstein and Holland, 2005; Borenstein, 2005. Holland and Mansur, 2006; Joskow and Tirole, 2007; Allcott, 2011, 2012). These efficiency

${ }^{*}$ Corresponding author: Phone: + (49)-331-288-2423

Email address: chgamba@pik-potsdam.de (Christian Gambardella) 
gains are commonly seen to rise in markets where energy supply and thus energy prices become increasingly volatile due to increasing shares of variable renewable energy (VRE) supply from wind or solar power (Leautier, 2014, Mills and Wiser, 2014, ACER, 2014, IEA, 2016).

We put this intuition into perspective by arguing that policy and regulatory measures should also be taken into account when assessing the change in efficiency gains from RTP at high VRE shares. Hence, we consider both the long-run electricity price effects of carbontax-induced VRE entry and excess capacity entry caused by administratively determined reliability standards. We do so by applying a comparative static welfare analysis of increasing RTP consumer shares for varying VRE supply shares. Using a deterministic partial equilibrium model of a stylized electricity spot market calibrated to German market data, we simulate long-run equilibria with endogenous generation technology investment. Formally, the model builds largely upon Borenstein and Holland (2005) and mimics competitive wholesale and retail market equilibria for exogenous shares of real-time and flat priced consumers in total electricity demand.

Wholesale price volatility is an intuitive primary driver of benefits from RTP, since it implies that flat priced consumers simply over- and underconsume more often and more pronounced. Higher RTP shares thus should increasingly improve allocative efficiency when VRE penetration rates rise, given the latter leads to higher price volatility. However, this intuition ignores the dependence of investment in VRE capacity on tax or subsidy measures, which in turn affect the long-run wholesale and retail price distribution both directly through (retail) price markups and indirectly via induced changes in the supply technologie portfolio. Benefits from RTP are thus not only determined by price volatility. We find that welfare gains from exogenous RTP share increases change nonmonotonously with the carbon tax and strictly rise with the induced VRE share. Notably and in contrast to common intuition, this implies that even at relatively high VRE shares welfare gains from RTP can be much lower than without VRE supply, and that welfare gains are only higher beyond a critical carbon 
tax level and VRE share. This is not so much explained by a corresponding change in price volatility, but rather by two opposing effects on the long-run wholesale price distribution following in particular from changes in the supply technology portfolio. First, the mass of the price distribution shifts to comparatively high levels as carbon taxation raises the marginal costs of electricity supply by carbon emitting generation technologies. As long as the tax does not induce VRE investment it entails only this price inflation effect, thereby reducing particularly the benefits from switching to RTP and thus the welfare gains from increasing RTP. Second, after a certain level carbon taxation triggers VRE entry and the fraction of prices equaling zero rises as electricity is increasingly supplied at zero marginal production cost. Since prices are high on average, this price effect implies high price spreads faced by consumers switching to RTP, which also results in higher overall welfare gains from RTP.

In addition to this, we analyze the welfare gains from increasing RTP under the assumption of inefficiencies arising from exogenous reliability standards that induce excess reserve capacity entry. Reliability-of-supply-issues are inherently linked to common lack of price responsive electricity demand and are also often seen to become more urgent with rising market penetration by VRE technologies. Since time-invariantly priced consumers are inable to react to capacity scarcity and thus to signal their need for reliable supply, administratively determined reliability targets are often regarded as necessary in most electricity markets (Crew et al., 1995; Joskow and Tirole, 2007; Cramton et al., 2013). These targets are regularly imposed as planning reserve margins (PRM), which define mandatory reserve capacity levels in excess of peak demand and which are implemented as complementary mechanisms such as capacity markets in many power systems (Pfeifenberger et al., 2013). $\left.\right|^{1}$

To capture this, we assume a systems with a PRM constraint and the challenge to accommodate increasing supply fluctuations from VRE. In such a system, regulators may be

\footnotetext{
${ }^{1}$ While not necessarily using explicit PRMs, most regulatory authorities seek to fulfill an explicitly defined reliability requirement such as the 0.1 day/year (one-day-in-ten-years) Loss-of Load-Expectation (LOLE) standard, for instance.
} 
confronted with a trade-off: either rolling out more costly smart-metering infrastructure to enable more consumers to raise consumption during periods of abundant VRE supply, or to save in costly reserve capacity entry through energy conservation during tight market situations by exposing relatively few incumbent RTP consumers to scarcity prices. Previous work on this shows that in a market without VRE technologies the potential cost savings from reduced excess reserve capacity entry due to scarcity pricing could far outweigh the comparative welfare gains from raising the share of RTP consumers beyond a moderate level (Allcott, 2012). We complement this by illustrating that in a market with increasing VRE entry, and thus increasing supply at zero marginal costs, allocative inefficiency caused by excess entry of reserve capacity becomes less significant. Instead, allocative efficiency increasingly depends on enabling more consumers to raise consumption during periods of relatively "cheap" and abundant VRE supply. Hence, the higher the VRE share, the higher the RTP share at which energy conservation by incumbent RTP consumers becomes more beneficial than further increasing the RTP share.

The paper proceeds as follows. In section 2 we present further political and regulatory background on key assumptions and embed our work in the related literature. Subsequently, we present an adaptation of the partial equilibrium model of dynamic retail pricing by Borenstein and Holland (2005) and Allcott (2012) in section 3. Data, calibration and central simulation results are presented in sections 4 and 5, respectively. Section 6 concludes.

\section{Variable renewable energy supply and the need for price responsive demand}

Regulatory authorities in Europe have recognized demand sided flexibility as an integral part of a low carbon power market (ACER, 2014), which is also reflected in the rising number of simulation studies on the effect of increasing demand response (DR) resources on total system costs in European power markets. Their findings mainly suggest that DR could represent one of the most efficient options to accommodate increasing intermittent supply from high VRE shares (Bertsch et al., 2016; Brouwer et al., 2016; Connect Energy Economics, 2015). Our approach differs from these system cost optimization analyses in two important 
ways. First, methodologically and most importantly we apply partial equilibrium modeling instead of a social planner approach, allowing us to recreate real market inefficiencies arising from a situation where most consumers face a time-invariant retail price. Second, we analyze and decompose consumer welfare gains from higher RTP consumer shares in total demand instead of focusing on total system cost differences. This allows us to delineate the effects on the potential welfare gains from RTP caused by supportive policy measures such as VRE subsidization or carbon taxation inducing VRE diffusion.

While modeling consumer behavior under real-time pricing in a similar way as we do, Mills and Wiser (2014) model exogenous VRE entry and thereby abstract from price effects of supportive policy measures in the long-run equilibrium. In contrast, we model endogenous VRE investment driven by carbon taxation, which will put some of the findings in Mills and Wiser (2014) into relation. Their simulation of the WECC transmission region in the U.S. yields that welfare gains from increases in the RTP share rise in a convex fashion with the penetration rate of wind and solar power. This is contrary to our central finding of nonmonotonously changing welfare gains from given RTP share increments. For instance, the welfare gains of RTP found at moderate VRE supply shares of about 30-40\% in consumption exceed those without VRE supply by $80-90 \%$, whereas we find that at these VRE shares RTP is actually less beneficial than without VRE supply.2 In this regard we also complement Leautier (2014) who analytically derives a closed form solution for the marginal social value of RTP. He illustrates that the marginal value rises directly with the variance of electricity prices, however, only for a market without VRE technologies. The author accordingly concludes that social benefits of RTP rise with VRE supply shares presuming price volatility rises as well. Yet, as stated above our main aim is to demonstrate that explaining benefits from RTP under high VRE supply also requires to account for the mechanism inducing VRE enter in equilibrium, which in our base case is an exogenous carbon tax. We also present

\footnotetext{
${ }^{2}$ Note that Mills and Wiser (2014) focus on the value of RTP in accommodating intermittent VRE supply which to this end is measured as the change in the market value of VRE technologies when all consumers are on RTP. Therefore, ignoring endogenous entry and supportive instruments seems appropriate for this cause.
} 
welfare changes from RTP when VRE are subsidized, which delivers similar results albeit due to a different effect on retail energy prices.

A uniform carbon tax as the only instrument to foster VRE investment does not represent common regulatory practice in most electricity markets that have faced a substantial diffusion of VRE technologies. Instead, VRE subsidies of some form are widespread. Economic justification for direct or indirect VRE subsidy schemes often bases on a second-best climate policy argument or on positive externalities from knowledge-spillovers from VRE deployment (Borenstein, 2012, Kalkuhl et al., 2013, Green and Léautier, 2015). However, we resort to assume that the negative externality from carbon emissions represents the only market failure and suppose that a uniform carbon tax is the most cost-efficient instrument available to address this market failure (cf. Fell and Linn (2013); Cramton et al. (2015); Gollier and Tirole (2015); Weitzman (2015)).

Apart from the mentioned aspects, one of our main contribution with this work is to link previously unrelated strands of literature. The first is dealing with the welfare impacts of RTP in electricity markets with conventional technologies only Borenstein and Holland, 2005: Borenstein, 2005; Holland and Mansur, 2006, Joskow and Tirole, 2007). With the exception of Chao 2011 ${ }^{3}$ the other strand analyzes long-run equilibrium impacts of intermittent VRE supply either ignoring to analyze the welfare gains from RTP share increases (cf. Bushnell, 2010, Green and Vasilakos, 2011; Green and Léautier, 2015) and/or ignoring endogenous VRE investments (cf. Green and Vasilakos, 2011; Mills and Wiser, 2014).

\section{Model}

Our electricity and capacity market model is an adaptation of approaches by (Borenstein and Holland, 2005) and (Allcott, 2012), which we extend particularly regarding the investment in VRE technologies driven by carbon taxation and the combined effects on retail rates.

\footnotetext{
${ }^{3}$ Unlike us, Chao (2011) does not compare the differential impacts of varying carbon tax levels on the welfare gains from RTP.
} 


\subsection{Electricity demand}

Wholesale electricity supply has to match aggregate demand $\bar{Q}_{t}(p)$ in each hour $t \in$ T. In line with previous work, we assume that consumers have the same underlying demand in $t, Q_{t}(p)$ with $\frac{\partial Q_{t}}{\partial p}<0$. An exogenously given share of consumers, $\alpha \in[0,1]$, consists of RTP customers facing an hourly varying retail electricity price $p_{t}$, while the remaining $(1-\alpha)$ flat rate consumers pay the time-invariant tariff $\bar{p}$. Additionally, consumers pay separately for generation capacity and reserves. While flat rate consumers always pay a constant mark-up pc per unit of electricity, RTP consumers pay either a time-varying capacity price ${ }^{4} p c_{t}$ or the same constant mark-up as flat rate consumers. That is, RTP consumers either face scarcity prices or they do not, which is described in more detail below. Hence, each $t$ RTP customers consume $\alpha Q_{t}\left(p_{t}, p c_{t}\right)$ or $\alpha Q_{t}\left(p_{t}, p c\right)$ units of electricity and flat rate consumption equals $(1-\alpha) Q_{t}(\bar{p}, p c)$, yielding hourly aggregate wholesale and retail demand as $\bar{Q}_{t}\left(p_{t}, \bar{p}, p c_{t}, p c\right)=\alpha Q_{t}\left(p_{t}, p c_{t}\right)+(1-\alpha) Q_{t}(\bar{p}, p c)$ or $\bar{Q}_{t}\left(p_{t}, \bar{p}, p c\right)=$ $\alpha Q_{t}\left(p_{t}, p c\right)+(1-\alpha) Q_{t}(\bar{p}, p c)$, respectively. Increasing $\alpha$ makes aggregate demand more reactive to time-varying prices so that it rotates around the point $\left(\bar{Q}_{t}\left(p_{t}, \bar{p}, p c_{t}, p c\right), \bar{p}\right) !^{5}$ For the simulation, we assume an iso-elastic demand function $Q_{t}(p)=a_{t} p^{\epsilon}$, where $\epsilon<0$ is the constant own-price elasticity and $a_{t}$ a scaling parameter capturing structural demand variations between hours. This gives hourly aggregate demand under scarcity pricing, for instance, as $\bar{Q}_{t}\left(p_{t}, \bar{p}, p c_{t}, p c\right)=\left[\alpha\left(p_{t}+p c_{t}\right)^{\epsilon}+(1-\alpha)(\bar{p}+p c)^{\epsilon}\right] a_{t}$.

\subsection{Electricity supply and capacity investment}

There are $I$ generation technologies available indexed by $i=\{1, \ldots, I\}$ where $V \subset I$ and $N V \subset I$ is the subset of variable renewable (VRE) technologies and nonvariable, carbon

\footnotetext{
${ }^{4}$ This is a slight deviation from the representation of dynamic retail capacity prices in Allcott (2012), where both the energy and capacity component are subsumed under one hourly scarcity price. We explain this modification below.

${ }^{5}$ Since for $p_{t}>\bar{p}\left(p_{t}<\bar{p}\right)$ total demand $\bar{Q}_{t}(\cdot)$ will be lower (higher) after $\alpha$ has increased.
} 
emitting technologies ${ }^{6}$ respectively. Installed capacity of each nonvariable technology $i$ $K_{i}^{N V}$ is always fully available, that is $a v_{i t}^{N V}=1 \forall i \in N V, t \in T$, whereas capacity of VRE technology $i K_{i}^{V}$ is time-varyingly available, capturing varying wind speeds or solar radiation, for instance, such that $a v_{i t}=[0,1] \forall i \in V, t \in T$. Up to available capacity av ${ }_{i t} K_{i}$, technology $i$ produces each megawatt hour (MWh) of electricity at constant marginal costs $m c_{i}(\tau)$, where $\tau$ is the exogenous per unit carbon emissions tax which increases marginal production costs of nonvariable technology $i$ by $\frac{\partial m c_{i}^{N V}}{\partial \tau}>0$. Annuitized fixed costs of capacity amount to $f c_{i}$ units per megawatt (MW) and year. Nonvariable technologies can be ordered by increasing marginal production $\operatorname{costs} m c_{i}^{N V}>m c_{j}^{N V} \forall i>j$ and decreasing annual fixed $\operatorname{costs} f c_{i}^{N V}<f c_{j}^{N V} \forall i>j$, principally allowing for entry of each technology type in the longrun equilibrium Crew et al., 1995).7 Since VRE technologies produce at negligible or zero marginal costs without emitting carbon dioxide $\left(C O_{2}\right)$, that is $m c_{i}^{V}=0$ and $\frac{\partial m c_{i}^{V}}{\partial \tau}=0 \forall i \in V$, they become relatively cheaper than nonvariable technologies as the carbon $\operatorname{tax} \tau$ is $\operatorname{raised}$ from zero. Likewise, nonvariable technology $i$ becomes relatively cheaper than technology $j$ given that $\frac{\partial m c_{i}}{\partial \tau}<\frac{\partial m c_{j}}{\partial \tau} \forall i \neq j$, resulting in corresponding portfolio changes.

By maximizing total annual profits $\pi_{i}\left(q_{i t}, K_{i} \mid w_{t}, r\right)$ under perfect foresight and perfect competition and thus taking wholesale electricity price $w_{t}$ as given, generators decide upon investment in capacity $K_{i}$ of technology $i$ and output $q_{i t}$. Output choice always bases on available installed capacity such that $q_{i t} \leq a v_{i t} K_{i} \forall t, i$. In addition to their short-run profits from energy sales $q_{i t}\left(w_{t}-m c_{i}\right)$, nonvariable technologies receive a separate, uniform capacity payment $r$, which is determined in the capacity market equilibrium discussed below. This

\footnotetext{
${ }^{6}$ This implies that we abstract from nonvariable and carbon nonemitting technologies such as nuclear energy. Doing so allows us to model strictly increasing VRE entry under carbon taxation and thereby to focus on its effects on the benefits of RTP. It further reflects particularly the German market situation in the long-run, which we simulate and where a nuclear-phase out has been determined. Moreover, this assumption may be justified by possibly decreasing profitability of nuclear energy technologies due to lower full load hours and/or increasing quasi-fixed costs following from more frequent starting and shut down operations with high VRE shares.

${ }^{7}$ While variable technologies are at the low end of marginal cost assumption, their effective annuitized fixed costs per $\mathrm{kW}$ are usually relatively high due their low average capacity availability. This enables entry of higher marginal/higher nominal fixed cost technologies in the long run equilibrium.
} 
gives their total annual profit as

$$
\pi_{i}^{N V}\left(q_{i t}, K_{i} \mid w_{t}, r\right)=\sum_{t}^{T}\left[w_{t}-m c_{i}^{N V}\right] q_{i t}^{N V}+r K_{i}^{N V}-f c_{i}^{N V} K_{i}^{N V}
$$

Each VRE technology $i \in V$ fully depends on remuneration from energy sales and thus makes annual profits equal to

$$
\pi_{i}^{V}\left(q_{i t}, K_{i} \mid w_{t}\right)=\sum_{t}^{T}\left[w_{t}-m c_{i}^{V}\right] q_{i t}^{V}-f c_{i}^{V} K_{i}^{V}
$$

Each generator using technology $i$ optimally produces at capacity and supplies $q_{i t}=a v_{i t} K_{i}$ each time marginal revenue is larger than marginal costs, that is $w_{t}>m c_{i}$. If $w_{t}=m c_{i}$ a generator is indifferent between any output level, that is $q_{i t} \geq 0$, but produces nothing if $w_{t}<m c_{i} \unlhd^{8}$ Hence, each generating unit has an inverse L-shaped supply curve so that aggregate wholesale supply is a step function (merit order) where each plateau reflects the constant marginal costs of all technologies present in equilibrium (cf. Holland and Mansur, 2006).

Under perfect competition, generators invest in capacity of nonvariable technology $i$ until annuitized fixed costs per unit $f c_{i}$ equal cumulated short-run profits $\sum_{t}^{T}\left[w_{t}-m c_{i}\right]$ plus the price of capacity and reserves $r^{9}$

$$
\sum_{t}^{T}\left[w_{t}-m c_{i}^{N V}\right]+r=f c_{i}^{N V}, \forall i \in N V
$$

Likewise, generators invest in VRE capacity of technology $i$ until unit costs $f c_{i}$ equal the respective stream of short-run profits $\sum_{t}^{T}\left[w_{t}-m c_{i}\right]$ weighted by the hourly varying capacity

\footnotetext{
${ }^{8}$ With constant marginal costs $m c_{i}$ profit increases monotonically with output $q_{i t}$ given that $w_{t}>m c_{i}$ and is therefore maximized if producing at full available capacity.

${ }^{9}$ Reformulating (3) yields each generators competitive capacity market bid as $r^{b i d}=f c_{i}-$ $\sum_{t}^{T}\left[w_{t}-m c_{i}\right], \forall i \in N V$. The technology with the lowest earnings to refinance capacity costs will set the capacity market equilibrium price defined below.
} 
factor $a v_{i t}$

$$
\sum_{t}^{T}\left[w_{t}-m c_{i}^{V}\right] a v_{i t}=f c_{i}^{V} \forall i \in V
$$

As indicated above, we assume that investment in VRE technologies only become profitable if they become sufficiently cheap through carbon taxation. Equation (4) implies that VRE profitability is strongly determined by the technology specific correlation of capacity availability $a v_{i t}$ with the wholesale price $w_{t}$ (Lamont, 2008). If more capacity of the same VRE technology type enters, wholesale prices drop particularly when $a v_{i t}$ is relatively high, resulting in decreasing profitability. As shown by Green and Léautier (2015), this implies that supportive measures, such as the carbon tax in our case, likely require to rise disproportionately ${ }^{10}$ with the VRE share, ceteris paribus. Thus, the nonvariable technology portfolio of the long-run equilibrium with high VRE shares produces at rather high marginal costs. RTP consumers therefore face both relatively high prices during much of the time and relatively low, almost zero prices in the remaining time where VRE technologies set the wholesale price. As our simulation will illustrate, this counteracting change in the equilibrium wholesale price distribution, simultaneously reduces and raises the comparative benefits of RTP under high VRE shares. Depending on the net effect, welfare gains from higher RTP shares can thus be lower or higher than in a market equilibrium without VRE supply, which is explained in more detail below.

\subsection{The installed capacity market mechanism}

Following Allcott (2012), we model a perfectly competitive market for installed capacity by imposing a planning reserve margin (PRM) constraint either on nonvariable generation capacity entry $K^{N V}$ or on nonvariable generators' hourly output $q_{i t}^{N V}$. The PRM serves

\footnotetext{
${ }^{10}$ Quantitatively, the actual carbon tax level and increase to reach given equilibrium VRE shares will be highly sensitive to technology cost assumptions.
} 
to model distorted long-run entry of nonvariable capacity in excess of net peak demand, caused by administratively and not market determined reliability levels. As shown below, putting the PRM constraint either on capacity or output allows for mimicking the effects of a capacity market design without and with scarcity pricing of capacity, which triggers energy conservation by incumbent RTP consumers during hours of scarce production resources. In the latter case, "redundant" and thus inefficient entry of costly reserve capacity is mitigated, while excess entry occurs without scarcity pricing. We denote the scenario with scarcity pricing and with the PRM constraint on hourly output from nonvariable technology $i, q_{i t}^{N V}$, the Dynamic Installed Capacity (DICAP) regime. The corresponding PRM constraint is formally given as

$$
\sum_{i}^{N V} q_{i t}^{N V} \leq \frac{\sum_{i}^{N V} K_{i}^{N V}}{(1+m)}, \forall t
$$

Thus, the hourly aggregate supply curve becomes inelastic each time aggregate net demand, ${ }^{11}$ defined as total hourly demand less supply from VRE, exceeds installed nonvariable capacity less reserves $\frac{\sum_{i}^{N V} K_{i}^{N V}}{(1+m)} \sqrt[12]{ }$ Where net demand intersects with the inelastic part of supply then depends on the given RTP share and RTP consumers elasticity to $p c_{t}$ for given $p_{t}, \bar{p}$ and $p c$. The resulting shadow price $\rho_{t}$ at the intersection reflects the social cost of keeping $m$ percent of nonvariable generation capacity $K^{N V}$ as reserves in each hour $t$, that is

$$
\rho_{t} \begin{cases}>0, & \bar{Q}_{t}\left(p_{t}, \bar{p}, p c_{t}, p c\right)-\sum_{i}^{V} q_{i t} \geq \frac{\sum_{i}^{N V} K_{i}^{N V}}{(1+m)} \\ =0 & \bar{Q}_{t}\left(p_{t}, \bar{p}, p c_{t}, p c\right)-\sum_{i}^{V} q_{i t}<\frac{\sum_{i}^{N V} K_{i}^{N V}}{(1+m)}, \forall t\end{cases}
$$

Hence, the DICAP mechanism induces a time-varying scarcity price $\rho_{t}>0$ each time the PRM binds, which is assumed to be passed on to RTP consumers in real-time via the hourly

\footnotetext{
${ }^{11}$ Note that in equilibrium $\sum_{i}^{N V} q_{i t}^{N V}=\bar{Q}_{t}^{D}\left(p_{t}, \bar{p}, p c_{t}, p c\right)-\sum_{i}^{V} q_{i t}$ holds in each period $t$ (see below).

${ }^{12}$ Note that this conceptually differs from the "Augmented/Operational Reserve Demand Curve"-approach by Hogan (2005) in two ways. First, the constraint bites only if the (long-run) planning reserve margin is reached in any given hour as opposed to a short-run operational reserve margin (cf. Allcott, 2012). Second, investment in firm capacity and reserves is incentivized through inframarginal rents as well as the forward capacity payment $r$, yet not through occasional scarcity rents.
} 
capacity retail price $p c_{t}$. This triggers energy conservation by incumbent RTP consumers during these hours such that compliance with the reliability constraint is achieved. Note that $\rho_{t}$ does thus not affect hourly output decisions as it does not function as an hourly scarcity rent as such. Instead, we model a single forward payment per unit of installed capacity, $r=\sum_{t}^{T} \rho_{t}$, equaling the stream of scarcity shadow prices, which only affects investment decisions as $r$ is only included in the first order condition w.r.t. investment in $K_{i}^{N V}$ (cf. Eq. (3)) ${ }^{13}$ The capacity payment $r$ can be interpreted as the uniform clearing price of a hypothetical forward capacity market auction and provides a secure return on investments in nonvariable generation capacity installed in excess of projected peak demand (cf. Cramton et al. 2013). 14 Thus, since available supply always exceeds demand, wholesale price $w_{t}$ never exceeds marginal production costs of the most expensive technology deployed in equilibrium. ${ }^{15}$

This also applies under the Constant Installed Capacity (CICAP) regime, where RTP consumers now also pay a flat retail price for capacity $p c$ and thus do not reduce consumption when nonvariable resources are scarce. This mechanism is included via another market clearing condition postulating that nonvariable capacity $K^{N V}$ always exceeds aggregate net demand $\bar{Q}_{t}\left(p_{t}, \bar{p}, p c\right)-\sum_{i}^{V} q_{i t}$ by at least $m$ percent

$$
(1+m)\left[\bar{Q}_{t}\left(p_{t}, \bar{p}, p c\right)-\sum_{i}^{V} q_{i t}\right] \leq \sum_{i}^{N V} K_{i}^{N V}, \forall t
$$

\footnotetext{
${ }^{13}$ This represents a slight modification of the approach used by Allcott (2012) where scarcity prices are included in the hourly wholesale prices and thus short-run profits of all technologies. We do so mainly since we want to model a capacity market mechanism not providing VRE capacity remuneration.

${ }^{14}$ Apparently, $\rho_{t}$ is the payment necessary to make nonvariable generation capacity owners indifferent between producing electricity and providing reserve capacity in any particular hour where this is required (cf. Borenstein and Holland, 2003). This implies that each unit of nonvariable generation capacity receives a scarcity rent of $s r=\sum_{t}^{T} \frac{K^{N V}}{1+m} \cdot \frac{\rho_{t}}{K^{N V}}=\sum_{t}^{T} \frac{\rho_{t}}{1+m}$, where deflating by $1+m$ implies that scarcity rents are shared between nonvariable producers and reserve providers available in each period $t$ (cf. Allcott 2012).

${ }^{15}$ Consequently, the highest marginal cost technology denoted $I$ cannot gain short run profits, since $w_{t}$ can never rise above $m c_{I}^{N V}$. Therefore, in accordance with the zero-profit conditions implied in the assumptions above, the capacity market equilibrium price $r^{*}$ will always equate the fixed cost annuity of the most expensive marginal cost technology $I$ deployed in equilibrium.
} 
Note that the market clearing condition (7) differs from (5) as total demand depends on the time-invariant retail capacity price $p c$ only instead of also depending on the time-varying price $p c_{t}$. Thus, noting that $p c$ is a function of $\rho$, the constraint binds only once, that is in hour $\hat{t}$ where aggregate net demand $\bar{Q}_{\hat{t}}\left(p_{\hat{t}} \bar{p}, p c\right)-\sum_{i}^{V} q_{i \hat{t}}$ peaks. This gives the unique capacity shadow price $\rho$ as

$$
\rho \begin{cases}>0, & (1+m)\left[\bar{Q}_{t}\left(p_{t}, \bar{p}, p c\right)-\sum_{i}^{V} q_{i t}\right] \geq \sum_{i}^{N V} K_{i}^{N V}, \\ =0, & (1+m)\left[\bar{Q}_{t}\left(p_{t}, \bar{p}, p c\right)-\sum_{i}^{V} q_{i t}\right]<\sum_{i}^{N V} K_{i}^{N V}, \forall t .\end{cases}
$$

The shadow price $\rho$ of (8) equals the equilibrium capacity price $r$ paid to each unit of installed capacity from nonvariable technologies.

Since nonvariable technology capacity scarcity is defined by the PRM constraint, the respective shadow prices of both (5) and (7) reflect the marginal value of the exogenously determined reliability level rather than the social value of lost load (VoLL). In consequence, introducing scarcity pricing by changing from CICAP to DICAP then simply serves to mitigate the inefficiency from excess reserve capacity entry, which is induced via the PRM and the lack of energy conservation by RTP consumers under CICAP.

\subsection{Retail market equilibrium}

In the perfectly competitive retail market homogeneous retail firms buy electricity at wholesale prices $w_{t}$ and sell it on to the final consumers either at the real-time price $p_{t}$ or flat rate tariff $\bar{p}$. Additionally, retail firms have to procure nonvariable capacity at price $\rho$ under CICAP or at $\sum_{t}^{T} \rho_{t}$ under DICAP in proportion to net demand served plus the reserve margin, $(1+m)\left(Q_{t}(p)-\sum_{i}^{V} q_{i t}\right)$. We abstract from transmission and distribution costs. Under CICAP retailers refinance total capacity market payments, $\rho K^{N V}=$ $\rho(1+m)\left[\bar{Q}_{\hat{t}}\left(p_{\hat{t}}, \bar{p}, p c\right)-\sum_{i}^{V} q_{i \hat{t}}\right]$, by charging each consumer a constant and uniform capacity price $p c$ per unit of consumed electricity. Under DICAP, RTP consumers pay a time-varying capacity price $p c_{t}$, while flat consumers remain on the time-invariant price $p c$. 
For each customer group, retailers now spread and refinance the annual costs per unit of capacity and reserve demand, $(1+m) \sum_{t}^{T} \rho_{t}$, across scarcity hours where the PRM constraint binds and $\rho_{t}>0$ holds. Hence, while under CICAP total annual profits $\pi^{r t}$ equal

$$
\pi^{r t}=\sum_{t}^{T}\left(p_{t}-w_{t}\right) \alpha Q_{t}\left(p_{t}, p c\right)+\left(\bar{p}-w_{t}\right)(1-\alpha) Q_{t}(\bar{p}, p c)+p c \bar{Q}_{t}\left(p_{t}, \bar{p}, p c\right)-\rho K^{N V}
$$

$\pi^{r t}$ under DICAP is given by

$$
\begin{aligned}
\pi^{r t} & =\sum_{t}^{T}\left(p_{t}-w_{t}\right) \alpha Q_{t}\left(p_{t}, p c_{t}\right) \\
& +\left(\bar{p}-w_{t}\right)(1-\alpha) Q_{t}(\bar{p}, p c) \\
& +p c_{t} \alpha Q_{t}\left(p_{t, p} c_{t}\right)-\rho_{t}(1+m) \alpha\left(Q_{t}\left(p_{t}, p c_{t}\right)-\sum_{i}^{V} q_{i t}\right) \\
& +p c(1-\alpha) Q_{t}(\bar{p}, p c)-\rho_{t}(1+m)(1-\alpha)\left(Q_{t}(\bar{p}, p c)-\sum_{i}^{V} q_{i t}\right) .
\end{aligned}
$$

The first and second term represent retail profits from selling electricity to RTP and flat rate consumers in (9) and (10), respectively, while the subsequent terms comprise profits from capacity sales. For given $w_{t}$ and $\rho$ or $\rho_{t}$, each retailer determines the retail real-time price $p_{t}$, the flat tariff $\bar{p}$, the constant and time-variant retail capacity price $p c$ and $p c_{t}$, respectively, by maximizing $\pi^{r t}$. Free entry of retail firms and the absence of transaction costs of switching retailers, which we assume, imply that retailers earn zero-profits in equilibrium. Moreover, we exclude cross subsidization of costs in retail rates. Thus, the respective zero-profit condition $\sum_{t}^{T}\left(p_{t}-w_{t}\right) \alpha Q_{t}\left(p_{t}, p c, p c_{t}\right)=0$ and $\sum_{t}^{T}\left(\bar{p}-w_{t}\right)(1-\alpha) Q_{t}(\bar{p}, p c)=0$ with regard to the real-time electricity price $p_{t}$, and energy flat rate tariff $\bar{p}$ must hold under both DICAP and CICAP. This implies that the real-time retail price $p_{t}$ equals the electricity wholesale price $w_{t}$ in each period, that is $p_{t}=w_{t} \forall t$, while gives that the competitive flat price $\bar{p}$ is a flat 
demand weighted average of $\left\{w_{t}\right\}_{t}^{T}$ :

$$
\bar{p}=\frac{\sum_{t}^{T} w_{t} Q_{t}(\bar{p}, p c)}{\sum_{t}^{T} Q_{t}(\bar{p}, p c)}
$$

Likewise, revenues from capacity and reserve sales have to equate corresponding costs in equilibrium, such that $\sum_{t}^{T} p c \bar{Q}_{t}\left(p_{t}, \bar{p}, p c\right)-\rho K^{N V}=0$ has to hold under CICAP, giving the flat capacity price $p c$ as the total demand weighted average of total nonvariable generation capacity costs:

$$
p c=\frac{\rho K^{N V}}{\sum_{t}^{T} \bar{Q}_{t}\left(p_{t}, \bar{p}, p c\right)} .
$$

Breaking even with the costs of covering customers' net demand with sufficient capacity under DICAP implies that retailers determine the dynamic capacity price $p c_{t}$ as to warrant $\sum_{t}^{T} p c_{t} \alpha Q_{t}\left(p_{t}, p c_{t}\right)-\rho_{t}(1+m) \alpha\left(Q_{t}\left(p_{t}, p c_{t}\right)-\sum_{i}^{V} q_{i t}\right)=0$, while the constant capacity price $p c$ is chosen to yield $\sum_{t}^{T} p c(1-\alpha) Q_{t}(\bar{p}, p c)-\rho_{t}(1+m)(1-\alpha)\left(Q_{t}(\bar{p}, p c)-\sum_{i}^{V} q_{i t}\right)=$ 0 . Therefore, since charging $p c_{t}$ per unit of RTP energy consumption during scarcity hour $t$, retailers can deflate their capacity market costs in $t, \rho_{t}(1+m) \alpha\left(Q_{t}\left(p_{t, p} p c_{t}\right)-\sum_{i}^{V} q_{i t}\right)$ by $Q_{t}\left(p_{t}, p c_{t}\right)$. For each $t, p c_{t}$ is thus given as

$$
p c_{t}=\frac{(1+m) \rho_{t}\left(Q_{t}\left(p_{t}, p c_{t}\right)-\sum_{i}^{V} q_{i t}\right)}{Q_{t}\left(p_{t}, p c_{t}\right)} .
$$

The flat capacity price $p c$ is again a weighted average of the hourly capacity price $\rho_{t}$, where the weights now equal the ratio of hourly net demand plus reserves and total energy demand by flat consumers only:

$$
p c=\frac{\sum_{t}^{T}(1+m) \rho_{t}\left(Q_{t}(\bar{p}, p c)-\sum_{i}^{V} q_{i t}\right)}{\sum_{t}^{T} Q_{t}(\bar{p}, p c)} .
$$

The final hourly retail price for RTP consumers equals $p_{t}+p c_{t}$ under DICAP and $p_{t}+p c$ 
under CICAP. Flat rate customers pay $\bar{p}+p c$ each period and under both pricing regimes. ${ }^{16}$

\subsection{Wholesale market equilibrium}

For basically the same reasons given in Borenstein (2005) as well as Allcott (2012), the above model yields a unique long-run equilibrium in the wholesale, retail and capacity market. It is defined by the vector of installed capacity $\mathbf{K}$, the uniform capacity price for generators $r$, the flat electricity and capacity retail price $\bar{p}$ and $p c$. Moreover, it is defined by the set of equilibrium wholesale prices $\left\{w_{t}\right\}$ as well as retail prices $\left\{p_{t}\right\}$ and $\left\{p c_{t}\right\}$, which clear demand and supply in each hour $t$, that is $\bar{Q}_{t}\left(p_{t}, p c_{t}, \bar{p}, p c\right)=S\left(p_{t}\right) \forall t$ or $\bar{Q}_{t}\left(p_{t}, \bar{p}, p c\right)=S\left(p_{t}\right) \forall t$ under DICAP and CICAP, respectively, noting that the retail market equilibrium implies $w_{t}=p_{t} \forall t$

The wholesale clearing prices and quantities can be described in more detail by first noting that hourly aggregate supply is an upward sloping step function of $p_{t}$ due to the the clearly ranked marginal production $\operatorname{costs} m c_{i} \in\left[0, m c_{N V}\right]$, where we now use the index $i=0$ for denoting each technology from the variable technology subset $V$. For $0 \leq i \leq I$, the set of equilibrium electricity prices can be defined by the vertical segment between each step, $v_{i}=$ $\left\{t: m c_{i}<p_{t}<m c_{i+1}\right\}$, and the horizontal segment representing the marginal costs of the marginal technology $h_{i}=\left\{t: p_{t}=m c_{i}\right\}$ (cf. Green and Léautier, 2015). Let $u_{i t} \epsilon[0,1]$ denote the hourly degree of capacity utilization, that is the dispatch rate of technology $i$. Then on $h_{0}$, VRE technology $v \epsilon[1, V]$ produces at the margin so that demand and supply clear at $\bar{Q}_{t}(\mathbf{p})=\sum_{v=1}^{V} u_{v, t} a v_{v, t} K_{v}$, where $\mathbf{p}$ denotes the retail price vector either under DICAP or CICAP. On $h_{i}$ for $i \geq 2$, technology $i$ produces at the margin and VRE technologies at available capacity, therefore $\bar{Q}_{t}(\mathbf{p})=u_{i, t} K_{i}+\sum_{j=1}^{i-1} K_{j}+\sum_{v=1}^{V} a v_{v, t} K_{v}$. On $v_{i}$ demand intersects a vertical segment of the supply curve where technology $i \geq 1$ produces at capacity, while technology $i+1$ is not dispatched, which gives the equilibrium quantity as $\bar{Q}_{t}(\mathbf{p})=$

\footnotetext{
${ }^{16}$ Note that the competitive flat price $\bar{p}$ is not (second-best) optimal under general assumptions regarding the demand function, since optimal flat prices would reflect the relative consumption distortion in each hour, and thus would be a weighted average of the relative slopes of the demand curve (Borenstein and Holland, 2005). However, if assuming an iso-elastic demand function, as is done in the simulations below, the competitive and second-best optimal flat price are equal.
} 
$\sum_{j=1}^{i} K_{j}+\sum_{v}^{V} a v_{v, t} K_{v}$. Under DICAP, market clearing on $v_{I}$ implies that demand is rationed by the scarcity price $p c_{t}>0$, such that $\bar{Q}\left(p_{t}, p c_{t}, \bar{p},, p c\right)=\frac{\sum_{i=1}^{I} K_{i}}{(1+m)}+\sum_{v}^{V} a v_{v, t} K_{v}$.

Finally, recall that due to free entry each technology $i \in I$ of the long-run equilibrium capacity vector $\mathbf{K}$ earns zero-profits, that is $\pi_{i}=0 \forall i$.

\subsection{Welfare Effects}

Since retailers and generators do not obtain profits in the long-run market equilibrium, total welfare changes from increasing RTP shares are solely determined by surplus changes ${ }^{17}$ of consumers who switch from flat to real-time pricing, of consumers who remain on flat rates as well as of consumers who are already real-time priced (Borenstein and Holland, 2005). Increasing the share of RTP consumers from $\alpha^{0}$ to $\alpha^{1}$ entails corresponding changes in equilibrium retail real-time prices from $p_{t}^{0}+p c_{t}^{0}$ to $p_{t}^{1}+p c_{t}^{1}$ and in flat rate tariffs from $\bar{p}^{0}+p c^{0}$ to $\bar{p}^{1}+p c^{1}$. Total net consumer surplus changes of incumbent RTP consumers $\triangle C S^{R T P}$ equal the sum of all hourly surplus changes $\sum_{t}^{T}\left[\int_{p_{t}^{1}+p c_{t}^{1}}^{p_{t}^{0}+p c^{0}} \alpha^{0} a_{t} x^{\epsilon} d x\right]$, which under DICAP is given by

$$
\Delta C S^{R T P}=\sum_{t}^{T}\left[\frac{\alpha^{0} a_{t}}{\epsilon+1}\left(\left(p_{t}^{0}+p c_{t}^{0}\right)^{\epsilon+1}-\left(p_{t}^{1}+p c_{t}^{1}\right)^{\epsilon+1}\right)\right]
$$

Consumers who switch to RTP are paying $\bar{p}^{0}+p c^{0}$ before and $p_{t}^{1}+p c_{t}^{1}$ after switching under DICAP, yielding hourly net surplus changes as $\int_{p_{t}^{1}+p c_{t}^{1}}^{\vec{p}^{0}+p c^{0}}\left(\alpha^{1}-\alpha^{0}\right) a_{t} x^{\epsilon} d x$ and thus total surplus changes as

$$
\Delta C S^{S W I T C H}=\sum_{t}^{T}\left[\frac{\left(\alpha^{1}-\alpha^{0}\right) a_{t}}{\epsilon+1}\left(\left(\bar{p}^{0}+p c^{0}\right)^{\epsilon+1}-\left(p_{t}^{1}+p c_{t}^{1}\right)^{\epsilon+1}\right)\right]
$$

Under CICAP, $p c_{t}^{1}$ has to be substituted by the constant capacity adder $p c^{1}$ in 15 and (17). Finally, hourly surplus changes for customers who remain on the flat tariff equal

\footnotetext{
${ }^{17}$ As we us an isoelastic demand function, aggregate consumer surplus is unbounded, hence, we compute surplus changes.
} 
$\int_{\bar{p}^{1}+p c^{1}}^{\bar{p}^{0}+c^{0}}\left(1-\alpha^{1}\right) a_{t} x^{\epsilon} d x$ such that $\Delta C S^{F L A T}$ can be written as

$$
\Delta C S^{F L A T}=\sum_{t}^{T}\left[\frac{\left(1-\alpha^{1}\right) a_{t}}{\epsilon+1}\left(\left(\bar{p}^{0}+p c^{0}\right)^{\epsilon+1}-\left(\bar{p}^{1}+p c^{1}\right)^{\epsilon+1}\right)\right] .
$$

Borenstein and Holland $(2005)$ demonstrate that under general assumptions, to which we adhere, increases in the RTP share $\alpha$ yield losses for incumbent RTP customers $\left(\triangle C S^{R T P}<0\right)$, while flat rate customers usually benefit $\left(\triangle C S^{F L A T}>0\right)$ from reduced flat prices (positive pecuniary externality). Hence, total welfare gains are positive as long as the net surplus gains of switching consumers are sufficiently large.

From equation (16) it follows that the larger the spread between the previously paid flat retail price $\bar{p}^{0}+p c^{0}$ and real-time retail price $p_{t}^{1}+p c_{t}^{1}$, the larger is the hourly surplus loss $\left(\bar{p}^{0}+p c^{0}<p_{t}^{1}+p c_{t}^{1}\right)$ or gain $\left(\bar{p}^{0}+p c^{0}>p+p c_{t}^{1}\right)$ for a consumer adopting RTP. As shown in the subsequent part, carbon taxation and entry of VRE technologies have opposing effects on the distribution of equilibrium energy prices $\left\{p_{t}\right\}$ and accordingly on the hourly retail price spread $\left(\bar{p}^{0}+p c^{0}\right)-\left(p_{t}^{1}+p c_{t}^{1}\right)$ faced by switchers. As a consequence, given increases in RTP can result in larger or lower welfare gains from RTP than in a market equilibrium without carbon taxation and VRE supply.

Note that we do not compare actual net social welfare but only private net consumer surplus changes of RTP share increments for a given carbon tax. Thus, in our welfare analysis we ignore both the excess burden of carbon taxation and the utility gain from internalizing the negative externality from carbon emitting behavior.

\section{Data and calibration of the simulation model}

The model is numerically applied to simulate counterfactual carbon tax scenarios where the benchmark is a zero-carbon-tax equilibrium with fossil fueled generation technologies only. We simulate competitive long-run equilibrium prices and quantities for a representative year, that is for 8760 hours. To this end, the formal model is expressed as a mixed complementary problem (MCP) in GAMS (Rutherford, 1995) using the PATH solver algo- 
rithm (Ferris and Munson, 2000). We loosely calibrate the model to the German power system drawing on hourly price and load data of the German electricity spot market at the European Power Exchange (EPEX Spot SE) from 2013 18 The stylized set of supply technologies comprises onshore wind and solar photovoltaic (solar PV) as VRE technologies, lignite and hard coal as nonvariable base- and midload technologies as well as combined cycle and open cycle gas turbines (CCGT and OCGT) as peak and superpeak technologies. To compute technology specific marginal generation costs, $m c_{i}$, we use long-run projections on average fuel prices taken from IEA's World Energy Outlook 2014 (IEA, 2014) and on thermal efficiency rates based on a meta-study by Schröder et al. (2013). Fuel specific $\mathrm{CO}_{2}$-efficiency factors from Icha (2013) are used to determine marginal cost increases of carbon emitting technologies for corresponding increases in the carbon $\operatorname{tax} \tau$, i.e. $\frac{\partial m c_{i}^{N V}}{\partial \tau}>0$. Each technology's annualized fixed costs, also taken from Schröder et al. (2013), consist of overnight construction costs for the most part. Table 1 includes all relevant cost parameters of the stylized technology portfolio used for the simulation. Additionally, we apply publicly available data from 2013 provided by the German TSOs to compute the hourly capacity factors $a v_{i t}$ for each VRE technology. To do so, we divide hourly feed-in data from wind onshore and solar PV units by the respective installed capacity data.

Using the isoelastic demand function described in chapter 3.1, our numerical model results are largely driven by the parameter assumptions regarding own-price elasticity, $\epsilon$, and the distribution of the demand shifter, $a_{t}$. The demand shifter captures the characteristic seasonal and hourly aggregate consumption pattern and its distribution over 8760 hours is computed by using the mentioned price and load time series data. Since electricity demand in Germany is mostly nonresponsive to price, we assume that $\alpha=0$ and solve for $a_{t}$ by first

\footnotetext{
${ }^{18}$ EPEX clearing price data are publicly available at the Danish transmission system operator (TSO) Energinet.dk, while German load data can be obtained from the Network of European Transmission System Operators for Electricity (Entso-e). Note that we provide the model source code under an open-source license and the web links to the time series data sources in a supplementary file to this publication.

${ }^{19}$ The German grid is owned and operated by four private transmission system operators (TSOs): Amprion, 50Hertz Transmission, TransnetBW and Tennet TSO. Installed VRE capacity data are publicly available and provided by netztransparenz.de, which is a data platform initiated by the German TSOs.
} 
Table 1: Technology cost assumptions.

\begin{tabular}{llccccccc}
\hline Technology & \multicolumn{2}{c}{ Wind } & Solar PV & Lignite & Hard Coal CCGT & OCGT OCGT Oil \\
\hline Annualized Fixed Costs & {$\left[\mathrm{k} \in /\left(\mathrm{MW}^{*} \mathrm{a}\right)\right]$} & 136.43 & 76.49 & 145.85 & 125.40 & 88.65 & 49.32 & 40.32 \\
Marginal Production Costs & {$\left[\in / \mathrm{MWh}_{e l}\right]$} & 0.1 & 0.1 & 18.19 & 33.80 & 64.41 & 96.76 & 173.94 \\
$C_{2}$-Efficiency & {$\left[\mathrm{tCO}_{2} / \mathrm{MWh}_{e l}\right]$} & 0 & 0 & 0.88 & 0.73 & 0.33 & 0.51 & 0.68 \\
Thermal Efficiency & {$\left[\mathrm{MWh}_{e l} / \mathrm{MWh}_{t h}\right]$} & 1 & 1 & 0.45 & 0.46 & 0.61 & 0.39 & 0.39 \\
\hline
\end{tabular}

Notes: Marginal production costs shown in euro per megawatt hour (MWh) for a carbon tax equating zero. Annualized specific fixed costs (per MW and year) comprise overnight investment as well as fixed operation and maintenance costs. Cost annuities are calculated with a risk-free interest rate of $7 \%$, assuming lifetimes of 25 years for wind turbines solar PV, OCGT and CCGT, and 35 years for lignite and hard coal plants. While taking on a long-run perspective, prospected average fuel costs base on the "new policies scenario" for Europe, reflecting IEA's fuel price projections for 2030 (IEA 2014).

calculating the break-even retail flat rate of actual hourly spot market prices and inserting this flat-price and hourly load into the demand equation in 3.1 (cf. Borenstein, 2005).20 Finally, in the base case we set own-price elasticity $\epsilon$ to -0.05 as done by Allcott (2012), for instance, which is at the low end of empirical estimates (cf. Faruqui, A., Sergici, 2010, Allcott, 2011). We also check whether our qualitative findings hold for higher levels of price elasticity in the appendix. The PRM is arbitrarily set to $5 \%$ of net peak demand, but we also run simulations without and with higher PRMs, also shown in the appendix.

\section{Results}

We first analyze how exogenous increases in the portion of RTP consumers, starting from $\alpha=1 \%$, affect annual welfare as well as price and consumption distributions in long-run equilibrium under varying VRE shares in annual gross electricity consumption ${ }^{21}$ (GEC). To do so, we raise the exogenous carbon tax in discrete steps from zero up to $€ 450$ per ton of $\mathrm{CO}_{2}\left(t \mathrm{CO}_{2}\right)$, thereby increasing endogenous investment in VRE capacity, which accordingly results in higher VRE supply shares. For each increase in RTP, the basis of comparison is always the equivalent equilibrium without carbon taxation and VRE entry. We particularly compare equilibria with VRE shares of about $48 \%$ ( $€ 150$ per $\left.t C O_{2}\right), 57 \%\left(€ 250\right.$ per $\left.t C O_{2}\right)$, $63 \%$ ( $€ 350$ per $t \mathrm{CO}_{2}$ ) and $68 \%$ (€450 per $t \mathrm{CO}_{2}$ ). These scenarios approximately cover long-run VRE share projections in the German power system complying with German $\mathrm{CO}_{2}$

\footnotetext{
${ }^{20}$ In contrast to Borenstein (2005) but without loss of relevant information, we do not adjust hourly price data to yield zero-profits of installed generation capacity.

${ }^{21}$ Here, gross equals net consumption, since we neither model trade between adjacent markets nor do we include transmission losses or own-consumption of plants.
} 
emissions mitigation targets (cf. DLR et al., 2012, Bertsch et al., 2016). Importantly, results presented below are derived from simulating the DICAP scenario, noting that qualitative findings prevail under the CICAP scenario.

Subsequently, we basically repeat the comparative statics analysis above. But now we compare the benefits from enabling consumers to conserve energy when supply is scarce with the benefits from enabling more consumers to raise consumption when VRE supply at zero marginal costs is abundant. Therefore, we first compute the welfare gains from energy conservation via introducing scarcity pricing to a given share of incumbent RTP consumers ${ }^{22}$ i.e. from changing from CICAP to DICAP. Afterwards, we compute the welfare gains from increasing the respective RTP share under CICAP and compare these to the gains from introducing scarcity pricing for different VRE shares.

5.1. Welfare effects of increasing the RTP consumer share under increasing carbon taxation and variable renewable energy supply shares

Table 2 compares and decomposes total annual consumer surplus (TCS) gains from exogenous increases in RTP from $1 \%$ up to $20 \%$ and $50 \%$ of total demand in the base carbon tax and VRE share scenarios. The nonmonotonous change of TCS gains with rising carbon tax levels is indicated in column 3 of Table 2. Compared to the equilibrium without carbon taxation and VRE energy supply, these gains are on average $24 \%$ lower if the the tax is set at $€ 150$ per $t \mathrm{CO}_{2}$ and if the equilibrium VRE share amounts to $49 \%$ to $50 \%$ (compare first four rows). However, when the carbon tax is raised to $€ 250$ per $t \mathrm{CO}_{2}$ and the corresponding VRE share to $58 \%$ or $60 \%$, TCS gains range from $€ 231.49$ to $€ 532.61$ million per year and are thus about $12 \%$ to $16 \%$ larger than without VRE supply. If the VRE share rises by a few percentage points up to $64 \%$ and $70 \%$, TCS gains increase rapidly and are about $50 \%$ to $80 \%$ larger than without VRE entry. Yet, to reach these VRE shares requires the carbon

\footnotetext{
${ }^{22}$ We note that critical peak pricing (CPP) represents a similar concept of incentivizing energy conservation by retail customers during tight market situations. However, CPP rates may not necessarily be set to refinance capacity and reserve costs as do scarcity prices here.
} 
tax to be raised heavily from $€ 250$ per $t C \mathrm{O}_{2}$ to $€ 350$ and $€ 450$ per $t C \mathrm{O}_{2}$, respectively.23

Table 2: Decomposed total annual consumer surplus (TCS) changes from increasing the RTP share from $1 \%$ to $20 \%$ and to $50 \%$ under DICAP and for varying carbon tax levels (VRE shares).

\begin{tabular}{|c|c|c|c|c|c|}
\hline \multirow{2}{*}{$\begin{array}{c}\text { Carbon tax } \tau \\
\text { (VRE share in } \\
\text { GEC) } \\
{\left[€ / \mathrm{t} C O_{2}\right]}\end{array}$} & \multirow{2}{*}{$\begin{array}{c}\text { RTP consumer } \\
\text { share } \\
\\
\alpha\end{array}$} & \multicolumn{3}{|c|}{$\begin{array}{l}\text { Annual consumer surplus change } \\
{[\text { Emillion/year] }}\end{array}$} & \multirow[b]{2}{*}{$\begin{array}{c}\text { Switchers to } \\
\text { RTP }\end{array}$} \\
\hline & & Total & $\begin{array}{c}\text { Incumbent } \\
\text { RTP } \\
\text { Consumers }\end{array}$ & $\begin{array}{l}\text { Flat Rate } \\
\text { Consumers }\end{array}$ & \\
\hline 0 & $20 \%$ & 207.35 & -0.89 & 12.32 & 195.91 \\
\hline 0 & $50 \%$ & 460.29 & -3.101 & 66.67 & 396.73 \\
\hline $150(49 \%)$ & $20 \%$ & 156.23 & -2.25 & 17.73 & 140.74 \\
\hline $150(50 \%)$ & $50 \%$ & 353.85 & -3.005 & 31.081 & 325.77 \\
\hline $250(58 \%)$ & $20 \%$ & 231.49 & -1.88 & 22.38 & 211.00 \\
\hline $250(60 \%)$ & $50 \%$ & 532.61 & -2.815 & 36.921 & 498.503 \\
\hline $350(64 \%)$ & $20 \%$ & 302.23 & -1.51 & 20.57 & 283.18 \\
\hline $350(65 \%)$ & $50 \%$ & 712.07 & -2.631 & 39.223 & 675.478 \\
\hline $450(68 \%)$ & $20 \%$ & 370.62 & -1.22 & 17.65 & 354.19 \\
\hline $450(70 \%)$ & $50 \%$ & 888.19 & -2.521 & 41.237 & 849.477 \\
\hline
\end{tabular}

Figure $1 \mathrm{a}$ shows the TCS gains from raising the RTP share from $1 \%$ to $100 \%$ under the same carbon tax scenarios as before. Accordingly, comparing the blue with the red solid graph yields that given RTP share increases always entail higher benefits if carbon taxation and VRE supply are absent than if the tax equals $€ 150$ per $t C O_{2}$ and the VRE share reaches $48 \%$ to $52 \%$. At higher carbon tax and VRE share levels, raising the RTP share is always more beneficial and increasingly so as the divergence of the red dashed, dotted curves from the blue curve indicates.24 To illustrate the nonmonotonous relation between

\footnotetext{
${ }^{23}$ The disproportionate increase in the tax is a consequence of decreasing VRE market values with rising VRE entry, which is in line with previous findings by Green and Léautier (2015), for instance. Put simply, higher VRE entry lowers prices and thus short-run profits on average for each VRE technology particularly when capacity availability, $a v_{i t}$, is high, respectively. A certain VRE share under zero-profits then requires that prices rise sufficiently during times where VRE technologies produce along with more expensively producing and carbon emitting technologies. This is achieved by a disproportionately increasing carbon tax.

${ }^{24}$ This divergence exemplifies the complementarity between VRE supply and price responsive demand. The VRE share increases with the RTP share by roughly 4 to 5 percentage points in each carbon tax scenario, as shown by the numbers in brackets in Figure1a. The increasingly higher benefits from RTP result from the fact that VRE technologies are setting or suppressing wholesale prices to lower levels more often, since more RTP implies more wind and solar capacity entry in the long-run equilibrium (compare scenario 8 and 8 in Table A.3. Higher VRE entry, in turn, is caused by higher energy demand from RTP consumers who react
} 
carbon taxation and the benefits from RTP comprehensively, Figure $1 \mathrm{~b}$ gives the change in TCS gains from RTP when the carbon tax is raised from zero in discrete steps. TCS gains initially drop and reach a minimum as soon as the carbon tax equals $€ 60$ per $t C \mathrm{O}_{2}$ both for increases in $\alpha$ from $1 \%$ to $20 \%$ (blue curve) and to $50 \%$ (red curve). In either case this is the tax level at which VRE technologies first enter in equilibrium. Beyond this minimum, TCS gains rise monotonously in the carbon tax and corresponding VRE supply share. At $€ 210$ per $\mathrm{tCO}_{2}$ and a VRE share of about $54 \%$, the dashed curves intersect with the solid curves, respectively, which is where the TCS gains from raising the RTP share start to become larger than without VRE supply.

Note that this nonmonotonous change of welfare gains from RTP does not necessarily coincide with a corresponding change in price volatility as intuition would suggest. Comparing, for instance, the relative standard deviation (RSD) of real-time retail prices in the scenarios shown in Table A.3, gives that price volatility at a VRE supply share of about $58 \%$ is lower than without VRE supply. The corresponding welfare gains from RTP are, however, higher than in the scenarios without VRE supply (cf. Figure 1).25 This observation also holds for the scenarios with higher VRE shares. Yet, if we only compare the RSD of retail prices in the equilibria where VRE supply is present, price volatility and welfare gains from RTP both rise with the VRE share.

Consequently, our results show that the benefits of increasing the portion of RTP consumers may neither be necessarily higher in a market with high VRE supply shares nor can these benefits be solely explained by higher (lower) price volatility if they are higher (lower) ${ }^{26}$ Comparing column 3 and 6 in Table 2 gives that the bulk of aggregate surplus

to lower prices during times of high VRE supply, implying that VRE technologies make higher short-run profits at a given carbon tax level.

${ }^{25}$ Same holds for the RSD of the wholesale price (not shown). Beyond a VRE share of about $44 \%$ ( $€ 110$ per $t C O_{2}$ ), the standard deviation of wholesale and retail prices is higher than without VRE, yet welfare gains from RTP remain below those without VRE supply until the VRE share amounts to 54\% (€210 per $t C \mathrm{O}_{2}$ ).

${ }^{26}$ Table D.5 in Appendix D implies that these findings are robust for higher own-price elasticity assumptions, since annual welfare gains from given RTP increases are directly proportional to $|\epsilon|$ in each tax scenario. Likewise, Table C.4 in Appendix C shows that variations in the PRM do not qualitatively alter the above 


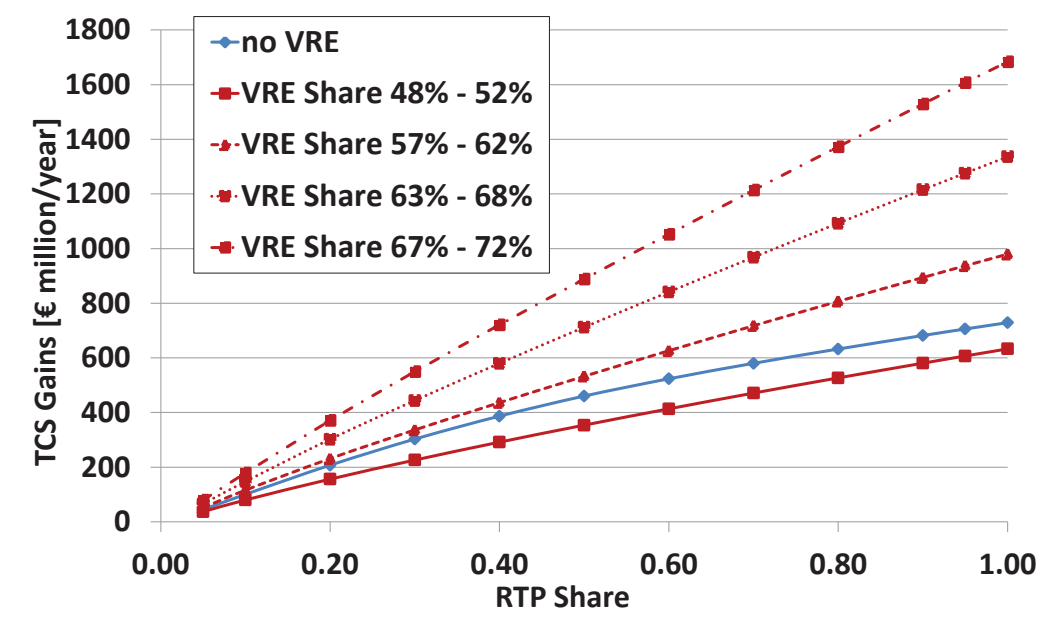

(a) Total annual consumer surplus gains (TCS) from increasing the RTP share from $1 \%$ for different VRE shares under DICAP.

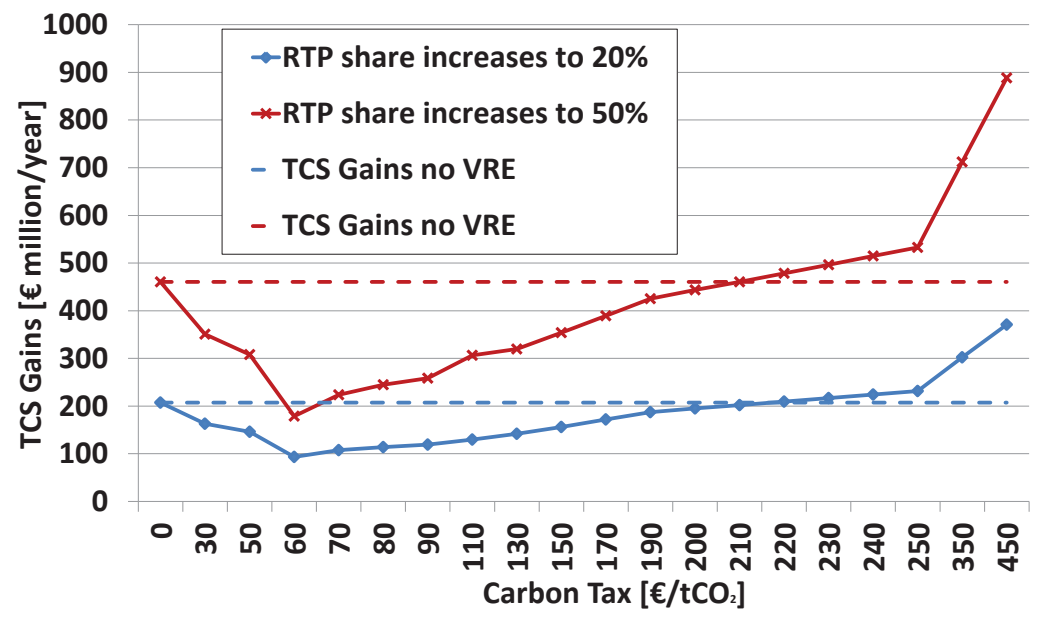

(b) TCS for given RTP share increases from $1 \%$ to $20 \%$ or to $50 \%$ and increasing carbon taxation (VRE supply shares).

Figure 1: Total annual consumer surplus (TCS) gains from increasing the RTP share from $1 \%$ under DICAP.

gains - more than $90 \%$ on average - is attained by consumers switching to RTP. Switching consumers' surplus gains are majorly determined by the spreads between their previously paid flat rate $\bar{p}$ and the set of real-time retail prices $\left\{p_{t}\right\}_{t}^{T}$ they pay after switching (cf. Eq. 16). We therefore argue that overall welfare gains from RTP and the observed effects from carbon taxation can be largely explained by how carbon taxation and VRE entry affect the

welfare results above. 
distribution of these price spreads. Hence, we focus on this aspect in the subsequent chapter.

\subsection{Price and consumption changes from increasing the RTP consumer share}

Consumers' net surplus gain from switching to RTP is directly proportional to the relative size and frequency of positive hourly retail price spreads $(\bar{p}+p c)-\left(p_{t}+p c_{t}\right)>0(\mathrm{cf}$. Eq. (16)). Intuitively, the more often consumers pay much less for consumption than before switching, the higher is their net surplus from switching to RTP. In this section we demonstrate that the nonmonotonous change in welfare gains from RTP shown above result from two opposing effects on the distribution of wholesale and retail electricity prices $w_{t}$ and $p_{t}$ caused by carbon taxation and VRE supply. As a result of these effects, the carbon tax initially depresses positive price spreads up to a point where the majority of price spreads becomes negative, that is $(\bar{p}+p c)-\left(p_{t}+p c_{t}\right)<0$. As soon as carbon taxation induces VRE entry, an initially much smaller share of positive price spreads becomes larger due to increasing zero marginal cost supply from VRE technologies. Further increases in the carbon tax and corresponding VRE share reduce the relative frequency of negative price spreads again, while simultaneously increasing size and frequency of positive retail price spreads.

Figure $2 \mathrm{a}$ and $2 \mathrm{~b}$ reflect these opposing effects. Figure $2 \mathrm{a}$ gives the ranked hourly consumption changes, $\triangle \mathrm{Q}$, when the RTP share, $\alpha$, changes from $1 \%$ to $20 \%$, where different curves reflect $\triangle \mathrm{Q}$ for the different carbon tax and corresponding VRE share levels as in the scenarios of Figure 1a. The solid blue line shows that after raising $\alpha$ in the equilibrium without tax and VRE supply, total hourly consumption rises on average by 0.39 GW in about $85 \%$ of all hours. During $15 \%$ of the time total demand is reduced slightly and occasionally by up to 4 gigawatts $(\mathrm{GW})$. This is contrasted by the red curves in Figure $2 \mathrm{a}$ showing that consumers in the equivalent equilibria with carbon taxation and VRE entry reduce consumption most of the time. Yet, during few but an increasing number of hours consumption rises by $3.5 \mathrm{GW}$ to $4 \mathrm{GW}$ on average, which is about ten times as large as the average consumption increase without $\operatorname{VRE}(\triangle Q=0.4 \mathrm{GW})$. The portion of hours where 


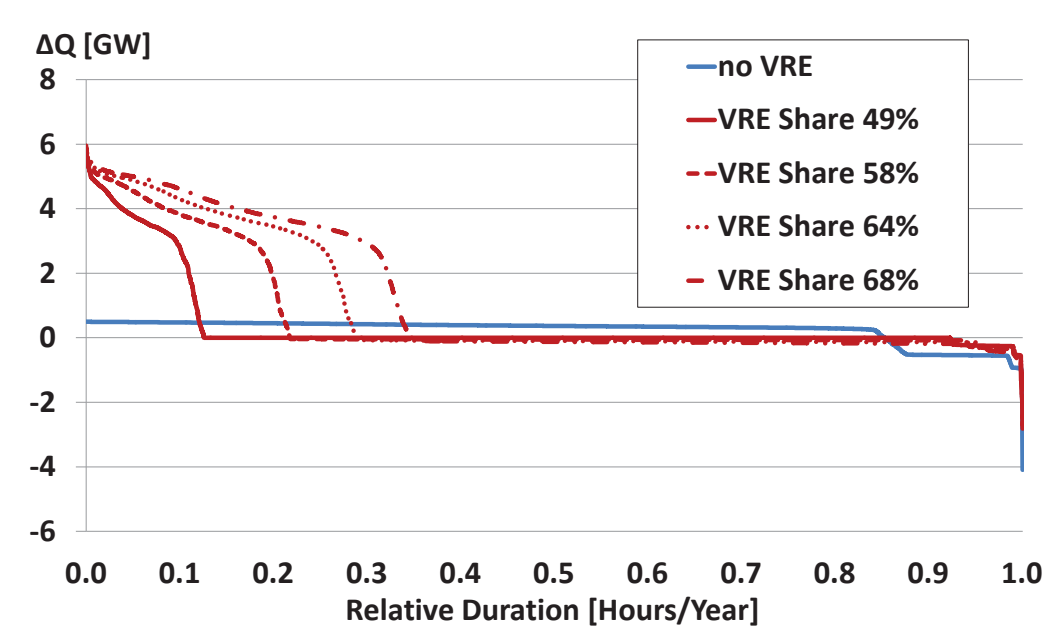

(a) Ranked distribution of hourly total demand changes in a representative year from increasing the RTP share to $20 \%$ and for varying VRE shares (in bracket) under DICAP.

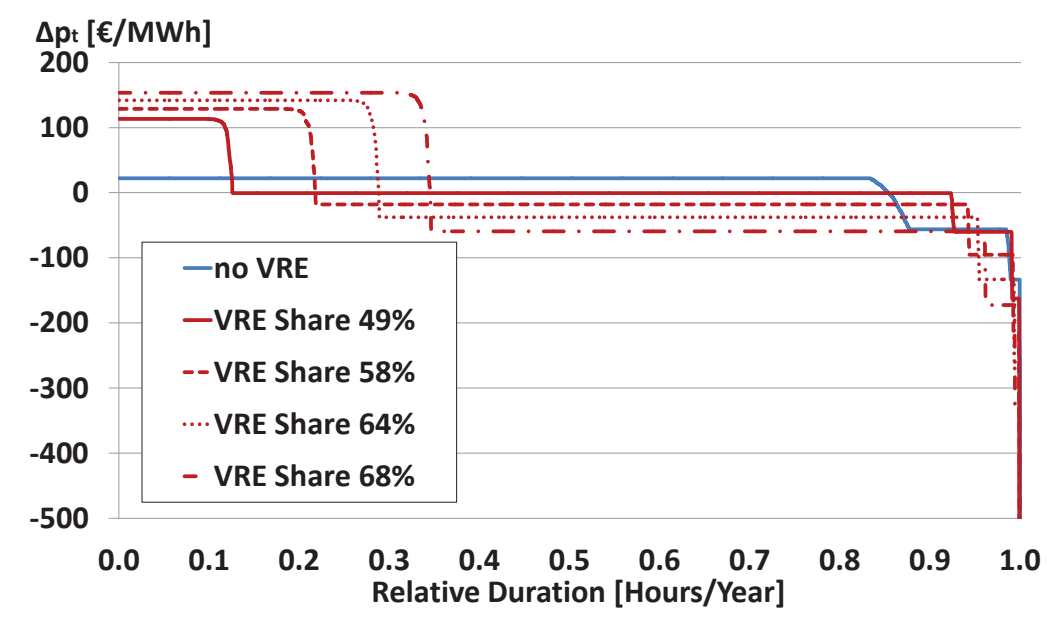

(b) Ranked distribution of hourly retail price changes when switching to RTP ,i.e. $\triangle p_{t}^{R T P}=(\bar{p}+p c)-\left(p_{t}-p c_{t}\right)$.

Figure 2: Ranked hourly retail price and total consumption changes for a given year under DICAP.

demand surges to these high levels rises from $13 \%$ to $34 \%$ of all hours, while the relative frequency of consumption reduction shrinks accordingly from $86 \%$ to $65 \%$. During few hours per year, maximum consumption increases are, for instance, even almost twelve times higher with a VRE share of $68 \%(\triangle Q=5.8 \mathrm{GW}$ versus $\triangle Q=0.5 \mathrm{GW}){ }^{27}$

\footnotetext{
${ }^{27}$ Due to the iso-elastic demand function specification, (RTP) consumption changes are relatively high at low prices and vice versa. Hence, while switching consumers face actually high price increases at originally high price levels for a large amount of time, their corresponding consumption reductions are relatively
} 


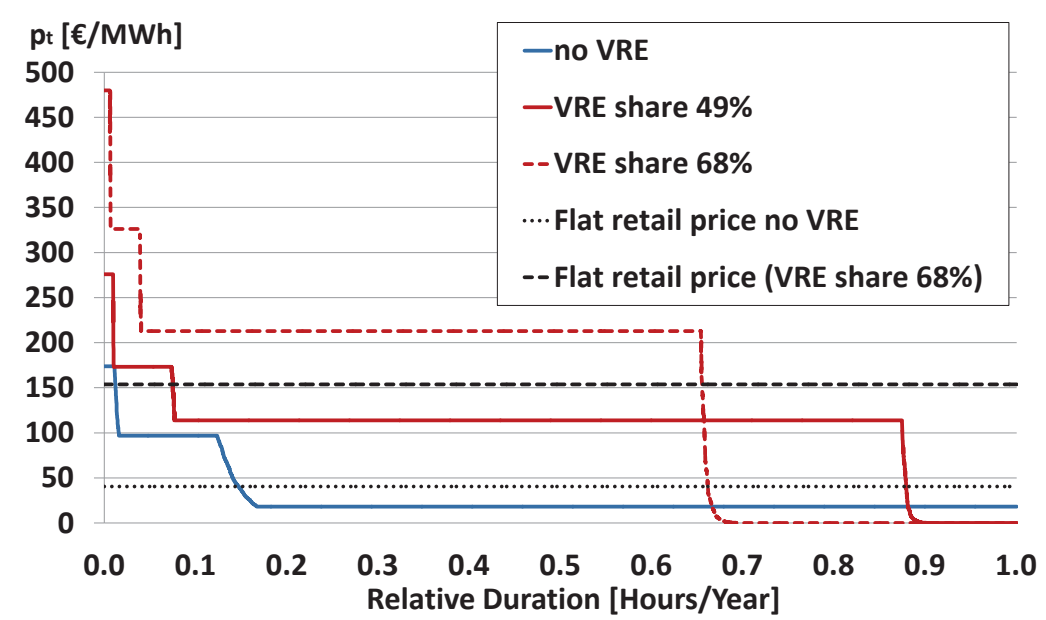

Figure 3: Ranked distribution of hourly retail electricity prices $p_{t}$ when $\alpha=20 \%$ against the equilibrium flat rate $\bar{p}+p c$ when $\alpha=1 \%$ for varying carbon taxes and VRE shares.

The ranked distributions of hourly price changes $\triangle p_{t}^{R T P}=(\bar{p}+p c)-\left(p_{t}+p c_{t}\right)$ in Figure $2 \mathrm{~b}$ perfectly mirror the corresponding distributions of consumption changes. Thus, consumers switching to RTP in the VRE equilibria (red graphs) face price increases, $\triangle p_{t}^{R T P}<0$, during $85 \%$ to $65 \%$ of all hours and heavy price drops during the remaining time. Without carbon taxation and VRE supply (blue graph) it is basically the other way round. In the latter case, switching consumers face an almost permanent yet small drop in the hourly retail price by about $22 €$ per MWh during roughly $80 \%$ of all hours and different price increases during the rest of hours. Note that without VRE, price drops can maximally amount to $(\bar{p}+p c)-m c_{1}^{N V}$, where $m c_{1}^{N V}$ denotes the marginal cost of the cheapest nonvariable technology in equilibrium. In contrast to this, switchers face a maximum price drop of $(\bar{p}+p c)$ when VRE supply is present in equilibrium, and thus pay about $€ 113$ to $€ 153$ per MWh less during only $13 \%$ to $34 \%$ of the time. Hence, while switching consumers now face negative price spreads far more often than without VRE supply, positive retail price spreads are six to seven times larger and increase in size as well as frequency with the carbon tax and the corresponding VRE share. 
The above changes in the distribution and level of retail price spreads can be explained by how carbon taxation reshapes the equilibrium distribution of hourly electricity prices $w_{t}=p_{t}$. Comparing the blue graph (no VRE supply) with the red graphs (VRE supply) in Figure 3 illustrates that the price distribution changes in two major ways. First, the higher the carbon tax, the higher the level at which the majority of prices settle (red graphs) such that $p_{t}$ equals at least $€ 113$ to $€ 212$ per $\mathrm{MWh}^{28}$ for $87 \%$ to $66 \%$ of the time, respectively. Intuitively, carbon taxation raises the marginal costs of the nonvariable, carbon emitting technologies, which set wholesale prices most of the time also at high VRE shares (low average capacity availability). Without carbon taxation prices thus settle at merely $€ 18$ per MWh (marginal costs of the lignite technology) during $83 \%$ of all hours. As the flat electricity rate $\bar{p}$ is a demand weighted average of hourly electricity prices (cf. Eq. (11)), the carbon tax inflates $\bar{p}$ and correspondingly the total flat retail rate $\bar{p}+p c$ in comparison to the equivalent flat rates obtained without carbon taxation and VRE supply ${ }^{29}$ Comparing the flat black lines in Figure 3, for instance, shows that $\bar{p}+p c$ amounts to $€ 154$ per MWh at $€ 450$ per $\mathrm{tCO}_{2}$ and is therefore about four times larger than the flat rate without carbon taxation. The large portion of negative price spreads, $\triangle p_{t}^{R T P}<0$, shown in the VRE share scenarios of Figure 2b, results from the fact that the inflation effect on $\bar{p}+p c$ is accompanied by a simultaneous rise in the VRE supply share, which increases the relative frequency of zero price hours from $13 \%$ to $34 \%$ in Figure 3. This is the second and opposing price distribution effect and suppresses $\bar{p}$ below $p_{t}$ during the majority of high price hours. The portion of high price hours shrinks accordingly from $87 \%$ to $66 \%$ of all hours. In turn, the frequency of positive retail price spreads, $\triangle p_{t}^{R T P}>0$, faced by switching consumers rises in Figure

moderate. In turn, consumption increases are relatively high when retail prices fall to zero at sufficiently high VRE supply.

${ }^{28}$ Marginal production costs of CCGT and corresponding equilibrium electricity prices amount to 113 $€ / \mathrm{MWh}$ at $150 € / \mathrm{t} C \mathrm{O}_{2}$ and to $212 € / \mathrm{MWh}$ at $450 € / \mathrm{t} C O_{2}$. Between $4 \%$ to $10 \%$ of the time OCGT gas and oil plants, representing the highest marginal production cost technologies in our simulation, have to complement CCGT and low VRE supply, raising electricity prices in the respective equilibrium to even higher levels of $173 € / \mathrm{MWh}\left(150 € / \mathrm{t} C \mathrm{O}_{2}\right)$ up to $480 € / \mathrm{MWh}\left(450 € / \mathrm{t} C O_{2}\right)$.

${ }^{29}$ Note that $p c$ falls with VRE entry as less firm capacity entry is needed to comply with the PRM on residual demand, but this drop in $p c$ is much lower than the increase in $\bar{p}$. 
3. also because of the increasing fraction of zero price hours. At the same time, the size of these positive price spreads increases, since the net effect of the tax is positive so that $\bar{p}+p c$ keeps rising.

In consequence, the changes in welfare gains from RTP under carbon taxation as shown in Figure 1 are caused by tax-induced and opposing price effects, which gradually change the relative size and frequency of the negative and positive price spreads faced by switching consumers. Initially, welfare gains from RTP share increments decrease with the carbon tax (Figure 1b), since up to $€ 60$ per $t C O_{2}$ the tax only raises the marginal costs of carbon emitting technologies without inducing any VRE entry. Accordingly, electricity prices only rise with the tax, implying that the average positive price spread faced by switching consumers only gets smaller. The latter is particular due to the fact that the marginal costs of the relatively high-carbon emitting (baseload) lignite technology rise faster than the originally higher marginal costs of the low-carbon emitting (midload) technologies (mainly natural gas CCGT units). Additionally, lignite capacity is partially crowded out by CCGT capacity ${ }^{30}$

As shown in Figure 1b, welfare gains from given RTP share increments start to rise again between $€ 60$ and $€ 70$ per $t C O_{2}$. At $€ 70$ per $t C O_{2}$, the technology portfolio changes abruptly, with lignite 31 capacity dropping by $61 \%$ (30 GW), CCGT capacity tripling to 32 GW and equilibrium PV as well as wind installed capacity increasing more than tenfold to 51 GW and 63 GW, respectively. While the VRE supply share surges from almost zero to $34 \%$, energy prices start to drop to zero during only $2 \%$ of the time. Nonvariable, high marginal cost technologies set prices during the remaining time due to the low average capacity factor of the VRE technologies ${ }^{32}$ As explained above, the ratio of high and low price hours changes with rising carbon taxation so that the demand weighted average price $\bar{p}$ keeps rising, while

\footnotetext{
${ }^{30}$ Nonetheless, at $60 € / t C O_{2}$ lignite still constitutes $61 \%$ ( $~ 50 \mathrm{GW}$ installed capacity) of the total generation portfolio.

${ }^{31} \mathrm{At} 75 € / \mathrm{tCO}$ the lignite technology is completely crowded out of the market.

${ }^{32}$ In our 2013 dataset the average capacity factor roughly amounts to $19 \%$ for wind and about $10 \%$ for PV. However, average capacity factors do not differ by much in other years since 2010, for which we have data available, too.
} 
real-time prices increasingly drop to zero. Thus, switchers face few but large positive price spreads along with many price spreads converging to zero. As soon as the tax equals $€ 110$ per $t \mathrm{CO}_{2}$, zero prices occur during $10 \%$ of all hours, pushing $\bar{p}$ below the marginal costs of the technology which sets prices most frequently in equilibrium (CCGT). The larger portion of price spreads therefore becomes negative similar to the price distribution in Figure $2 \mathrm{~b}$. Increasing the carbon tax further changes the distribution of price spreads faced by switchers as described above.

Consequently, our results show that the welfare gains from RTP change nonmonotonously with carbon taxation, since it shapes the long-run wholesale and retail price distribution in opposing directions. As shown in the section before, these carbon tax effects can imply that RTP is actually more beneficial without than with VRE supply, despite the observation that welfare gains from RTP strictly rise with the VRE supply share. This result would remain counterintuitive, if only considering the corresponding change in price volatility and ignoring the long-run technology portfolio and corresponding price effects of the VRE inducing instrument.

\subsection{Welfare, price and quantity effects of implementing scarcity pricing}

Introducing scarcity pricing -changing from CICAP to DICAP- is beneficial because of two basic reasons (cf. Allcott, 2012): On the one hand, all consumers benefit from incumbent RTP consumers' reaction to scarcity prices, $p c_{t}$, during hours of scarce generation capacity, since this lowers firm capacity entry and corresponding costs. On the other hand, particularly RTP consumers benefit from avoiding to pay for flat rate customers' consumption of scarce generation capacity. As the constant capacity mark-up per consumed kWh, $p c$, drops from their final hourly retail price, RTP consumers consume comparatively larger quantities in most hours. Simultaneously, they lower their share in total capacity payments by reducing demand when resources are scarce 33 While substantial efficiency gains can already

\footnotetext{
${ }^{33}$ The effect of time-varying capacity pricing on flat rate customers' annual surplus gains is ambiguous, since for any given flat price $\bar{p}$ the time-invariant capacity price $p c$ can either rise or decline. As explained, firm capacity entry is lower under DICAP as RTP consumers now reduce demand when capacity is scarce
} 
be obtained if only a small share of consumers is exposed to scarcity prices, the question considered here is whether it becomes relatively more beneficial to expose a higher fraction of consumers to price variations, given that VRE enter the market at an increasing rate and supply energy at zero marginal costs.

To analyze the relative efficiency gains of scarcity pricing and energy conservation for varying VRE shares, we compare the total annual surplus gains attained from putting incumbent RTP consumers on scarcity pricing with those attained from further raising the RTP share under CICAP. We find that with increasing carbon tax and VRE share, raising the share of RTP consumers before putting them on scarcity pricing becomes increasingly beneficial. Figure 4a shows the TCS gains from changing to DICAP for different carbon tax and VRE share levels. The black markers on each curve in Figure 4 a indicate the RTP share at which total annual welfare gains from introducing DICAP exceed those from further increasing the RTP share. While this RTP share amounts to $5 \%$ without VRE (blue curve) and with a $48 \%$ VRE share, it equals 20\%, $40 \%$ and $50 \%$ if the VRE share equals $57 \%, 63 \%$ and $67 \%$, respectively. Consequently, with rising VRE shares conserving energy during times of scarce capacity becomes less beneficial than raising consumers' ability to absorb abundant VRE supply. Put differently, as the amount of hours with low marginal cost supply from VRE rises, allocative efficiency depends rather on consuming relatively "cheap" electricity and less on saving in costly "excess" capacity induced by reliability targets. In this sense, the benefits from expanding RTP strictly increase with the carbon tax and VRE share. This result complements previous findings by Allcott (2012), showing that without VRE supply annual efficiency gains from introducing scarcity pricing far outweigh the benefits from further increasing the portion of RTP consumers beyond $10 \%{ }^{34}$

entailing lower firm capacity costs $r \cdot K^{N V}$ for all consumers. This pecuniary externality causes flat customers' unit capacity price $p c$ to shrink, ceteris paribus. Because RTP consumers can reduce their share in capacity payments by conserving energy though, $p c$ can also rise even if overall firm capacity costs decrease, given that $p c$ is simply a demand-weighted average of $p c_{t}$ and since flat consumers' relative contribution to these costs rises sufficiently when moving from CICAP to DICAP.

${ }^{34}$ Note that while Allcott (2012) compares total annual welfare gains from RTP under CICAP with those obtained from introducing DICAP at a higher RTP share $\alpha$, we compare the incremental gain from increasing 


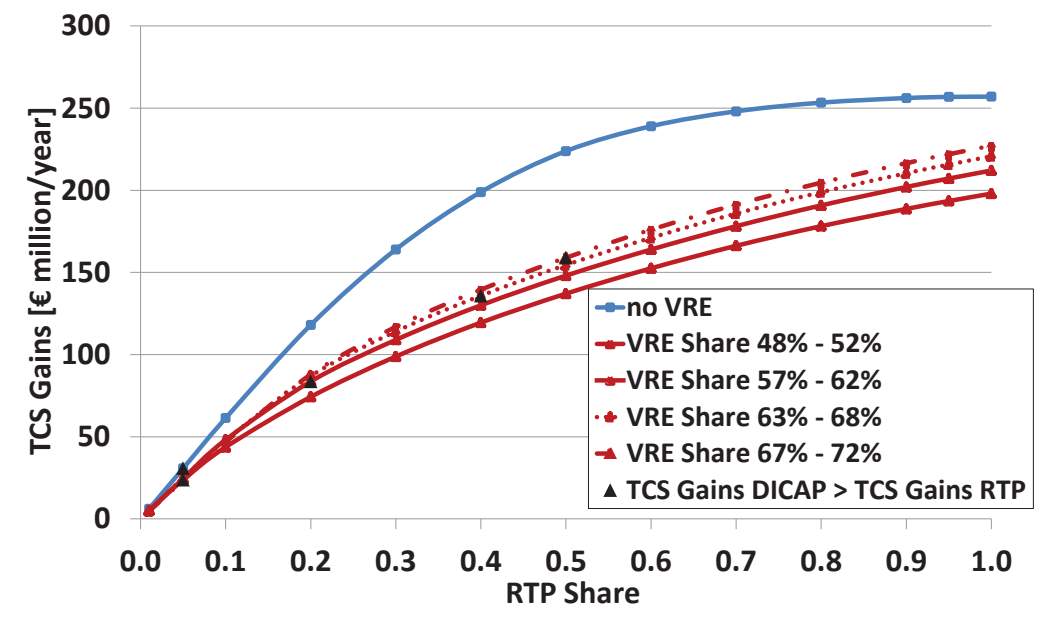

(a) Total annual consumer surplus gains (TCS) from changing to DICAP with black markers indicating the RTP share at which changing to DICAP becomes more beneficial than further increasing the RTP share.

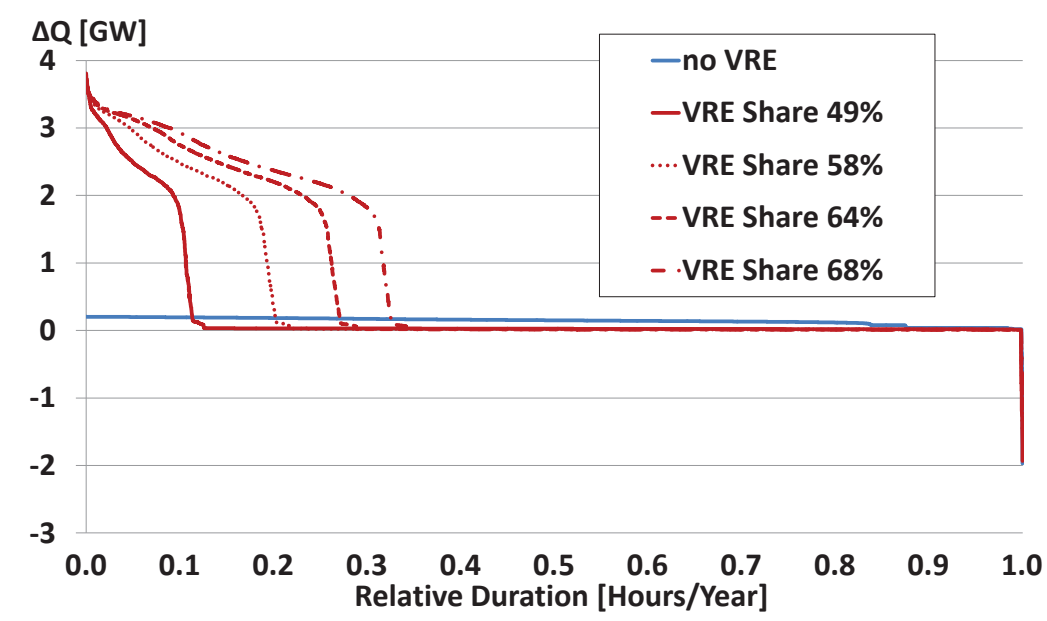

(b) Ranked distribution of total hourly demand changes from changing to DICAP.

Figure 4: Total annual consumer surplus gains (TCS) from introducing DICAP under varying shares of VRE

In line with the above result, Figure 4a also shows that benefits from exposing incumbent RTP consumers to scarcity prices decrease with carbon taxation and VRE entry. This is simply due to the fact that VRE capacity at least partially reduces the need for capacity entry from nonvariable technologies in order to comply with the given PRM constraint.

a given $\alpha$ under CICAP with the absolute surplus gains from changing to DICAP at this same $\alpha$. 
Comparing, for instance, scenarios 1 and 2 with 5 and 6 in Table A.3 gives that for the same PRM nonvariable capacity is about $12 \mathrm{GW}$ lower in the CICAP equilibria with a VRE share of about $57 \%$ than without VRE entry. Accordingly, capacity market payments are roughly $20 \%$ lower which reduces $p c$ by $€ 0.7$ per MWh. Since the price drop is thus relatively lower within each hour, RTP consumers do not increase consumption as much as without VRE supply, which is reflected by the large flat part of the red curves in Figure 4b. Average consumption increases amount to $20 \mathrm{MW}$ during $70 \%$ to $90 \%$ of the time, whereas without VRE consumption is increased by $140 \mathrm{MW}$ during almost $90 \%$ of all hours ${ }^{35}$ While relatively high consumption increases occur more frequently with rising VRE shares, the price drop $(p c)$ during these hours shrinks simultaneously. Thus, TCS gains from changing to DICAP increase again with the VRE share but remain strictly below those without VRE entry.

\subsection{Robustness and limitations}

The nonmonotonous change of welfare gains from RTP found above crucially hinges on the electricity price effects of carbon taxation. These price effects may not be prevalent in systems where high VRE supply shares are induced through subsidies like feed-in-tariffs, renewable portfolio standards or capacity payments or the like. VRE and nonvariable technologies with constantly low marginal production costs, such as coal fired power plants, for instance, may then conjointly enter in large capacities ${ }^{36}$ Electricity prices in the long-run equilibrium therefore keep resting at low levels most of the time and increasingly shift to zero as VRE shares rise. Contrary to the findings before, welfare gains from rising RTP shares may thus be strictly larger with VRE supply than without VRE supply. We check this by simulating equilibria with VRE capacity subsidization and still find that welfare gains from RTP change

\footnotetext{
${ }^{35}$ For the same reasons explained before, decreases by $\triangle p^{R T P}=p c$ at relatively high price levels result in relatively low absolute consumption increases and vice versa. Therefore, in the VRE market equilibria, consumption surges up to about $1 \mathrm{GW}$ to $4 \mathrm{GW}$ only in $10 \%$ to $30 \%$ of the time, which is when VRE technologies are setting wholesale electricity prices to zero. Without VRE, electricity prices reside mostly at $€ 18$ per MWh (marginal production costs of lignite plants) such that a drop in the final retail price by $p c$ leads to moderate, yet steady consumption increases as shown by the blue curve in Figure $4 \mathrm{~b}$

${ }^{36}$ This matches the current situation in the German electricity market where VRE have diffused rapidly due to fixed feed-in-tariffs, while lignite as well as hard coal technologies remain in the market and supply electricity for the largest part.
} 
nonmonotonously with the VRE supply share. Hence, at relatively low VRE shares RTP can be less beneficial and at relatively high VRE shares RTP can be (slightly) more beneficial than in a market without VRE supply (cf. Figure B.5a and B.5b in appendix B). This outcome mainly results from the unit tax to finance the subsidy on VRE capacity. The tax increases with the VRE share and is added on top of both the retail real-time and flat rate, while wholesale prices indeed settle at low levels and increasingly drop to zero with rising VRE shares. We explain this in more detail in appendix $\mathrm{B}$

Furthermore, we abstract from fossil fuel price dynamics. Including these could alter the respective equilibrium generation portfolio at given carbon tax levels from the one simulated here. For instance, both the replacement of coal fueled by gas fueled technologies and entry of VRE technologies could occur at lower carbon tax levels than in our simulations. The carbon-tax-induced change of the wholesale price distribution should, however, have the same direction as above. Hence, we think that this simplification affects results quantitatively rather than qualitatively.

Additionally, our welfare results may be positively biased since we ignore electricity storage technologies or cross-border trade and transmission capacity expansion to adjacent markets. Hourly price spreads could be lower and the price distribution may not shift to as high levels as in our simulations either of which implies comparatively lower welfare gains from RTP.

Yet, we also omit cross-price elastic consumption behavior and may therefore underestimate the benefits from RTP, respectively. Given consumption is lower in high price periods and higher in low price periods, welfare gains from RTP may also rise faster with the VRE share than in our simulations. Likewise, benefits from RTP could be comparatively higher if transmission constraints and locational pricing would be accounted for. As these constraints

\footnotetext{
${ }^{37}$ This result may be further complicated if accounting for rising quasi-fixed costs which generators could include in their bids at the wholesale market. Increasing VRE supply may require more frequent start up, shut down and ramping operations by nonvariable technologies which drive quasi-fixed costs up. The wholesale price distributions of the equilibrium with subsidy or carbon-tax-induced VRE may then be quite similar. If this would imply that positive price spreads for switching consumers become large, the overall welfare gains from RTP may still change nonmonotonously but rise stronger with the VRE share than in the example of appendix B.
} 
could become more binding with spatially unequally dispersed wind and solar resources, additionally signaling local transmission scarcity to RTP consumers could yield further and perhaps large savings in transmission capacity costs.

\section{Conclusion}

With rising shares of volatile electricity supply from variable renewable energy (VRE) sources such as wind and solar power, allocative efficiency gains from exposing electricity consumers to time-varying wholesale prices are widely presumed to rise. This work is to our knowledge the first to analyze this intuition by studying the welfare gains from raising the share of real-time retail pricing (RTP) among consumers when VRE shares increase endogenously. We particularly complement previous work by analyzing the changes in the potential benefits from RTP resulting from carbon-tax-induced VRE investment. For this we apply German power market data from 2013 to simulate partial long-run equilibria of a perfectly competitive electricity market.

Our main result complements the common intuition that benefits from RTP should strictly rise with VRE supply shares because of rising price volatility. We find that welfare gains from increasing the RTP share change nonmonotonously with the carbon tax level, but rise strictly with the induced VRE share. Due to this we can show that unless the carbon tax and corresponding VRE supply share reach a critical level, respectively, higher RTP shares at high VRE supply shares can in fact entail much lower benefits than without VRE supply. Beyond these critical levels, welfare gains from RTP can be up to twice as large as without VRE supply. Importantly, and in difference to the aforementioned intuition, wholesale price volatility is not a good predictor of welfare gains from RTP. The latter can be comparatively large although the corresponding price volatility is comparatively low and vice versa.

Rather than considering price volatility, we can explain the above welfare results by analyzing the carbon tax effects on the long-run wholesale price distribution. These price distribution effects are twofold and opposing. At low levels, the carbon tax only raises the

marginal costs of carbon emitting technologies without inducing VRE entry. Wholesale 
prices thus only rise on average so that particularly the benefits from switching to RTP decline with the carbon tax. As soon as the tax starts to cause entry of VRE technologies, which supply energy at zero marginal costs, the largest portion of the price distribution still settles at high price levels, but simultaneously an increasing portion of prices settles at zero, since electricity demand can occasionally be served by VRE capacity only. Therefore, consumer surplus gains from switching to RTP and thus overall welfare gains from increasing the RTP share start to rise again.

Additionally, we demonstrate that inefficiencies from excess capacity entry induced by exogenous reliability requirements become less significant with VRE entry than the efficiency gains from higher RTP shares. The benefits from saving in costly excess capacity through triggering energy conservation can nonetheless be quite substantial. These can be achieved by exposing incumbent RTP consumers to scarcity prices. But with rising VRE entry, allocative efficiency increasingly depends on enabling more consumers to raise consumption during periods of "cheap" and abundant VRE supply. The level of incumbent RTP consumers at which introducing scarcity pricing is more beneficial than further raising the RTP share therefore increases with the VRE share.

Our main contribution with this analysis is to provide economic intuition on how the benefits from RTP could be affected by energy policy measures and induced VRE supply - at least in electricity systems similar to the one represented in our simulations. We further emphasize that our results should not be misinterpreted as weakening the case for RTP implementation at high VRE shares, since introducing RTP is always beneficial in our simulations.

A crucial question in this regard remains whether much of the substantial welfare gains from RTP under high VRE supply can actually be realized, given that many retail customers could be rather reluctant to adopt RTP schemes (Borenstein, 2013). RTP adoption rates may be nonoptimal if, for instance, consumers misperceive their benefits from switching to RTP because they are inattentive to or imperfectly informed about their consumption costs (Ito, 2014; Jessoe and Rapson, 2014). Accordingly, one particular avenue for further research 
is to analyze optimal policies to correct for biased retail contract choices and thus to model nonoptimal RTP adoption.

\section{Appendix A. Selected simulation results}

Table A.3: Selected simulation results of the base PRM scenario.

\begin{tabular}{|c|c|c|c|c|c|c|c|c|}
\hline Scenario & 1 & 2 & 3 & 4 & 5 & 6 & 7 & 8 \\
\hline Market design & CICAP & CICAP & DICAP & DICAP & CICAP & CICAP & DICAP & DICAP \\
\hline RTP share $\alpha$ & 0.01 & 0.2 & 0.01 & 0.2 & 0.01 & 0.2 & 0.01 & 0.2 \\
\hline Carbon $\operatorname{tax} \tau\left[\in / \mathrm{t} C \mathrm{O}_{2}\right]$ & 0 & 0 & 0 & 0 & 250 & 250 & 250 & 250 \\
\hline VRE share in total consumption [\%] & 0 & 0 & 0 & 0 & 57.10 & 57.70 & 57.20 & 58.10 \\
\hline \multicolumn{9}{|l|}{ Equilibrium Quantities [GW] } \\
\hline Average & 52.87 & 52.99 & 52.88 & 53.13 & 49.90 & 50.14 & 49.93 & 50.65 \\
\hline Maximum & 75.53 & 74.50 & 75.36 & 71.27 & 71.44 & 73.67 & 71.63 & $\begin{array}{c}77.47 \\
0.55\end{array}$ \\
\hline \multicolumn{9}{|l|}{ Equilibrium Prices [ $€ / M W h]$} \\
\hline Relative standard deviation of $p_{t}[\sigma / \bar{p}]$ & 0.83 & 0.82 & 12.97 & 10.38 & 0.53 & 0.53 & 3.52 & 1.78 \\
\hline Average wholesale price $\bar{w}$ & 30.23 & 30.23 & 30.23 & 30.23 & 121.09 & 121.09 & 121.09 & 121.09 \\
\hline Maximum wholesale price $w_{t}$ & 173.94 & 173.94 & 173.94 & 173.94 & 343.94 & 343.94 & 343.94 & 343.94 \\
\hline Flat retail electricity price $\bar{p}$ & 33.48 & 33.48 & 33.48 & 33.48 & 122.75 & 122.75 & 122.75 & 122.75 \\
\hline Average hourly capacity price $p c_{t}$ & 0 & 0 & 42,340 & 3,849 & 0 & 0 & 40,704 & 2237.31 \\
\hline Max hourly capacity price $p c_{t}$ & 0 & 0 & 42,340 & 33,390 & 0 & 0 & 40,704 & 18,028 \\
\hline Flat capacity price $p c$ & 6.90 & 6.80 & 6.91 & 6.88 & 6.14 & 6.06 & 6.15 & 6.09 \\
\hline Flat retail price $\bar{p}+p c$ & 40.39 & 40.28 & 40.39 & 40.36 & 128.90 & 128.80 & 128.90 & 128.84 \\
\hline \multicolumn{9}{|l|}{ Equilibrium capacity entry [GW] } \\
\hline OCGT oil (peak) & 10.14 & 9.85 & 9.96 & 6.43 & 8.51 & 8.36 & 8.37 & 6.01 \\
\hline OCGT (peak) & 4.62 & 4.12 & 4.62 & 4.07 & 9.53 & 9.35 & 9.53 & 9.36 \\
\hline CCGT (peak) & 0 & 0 & 0 & 0 & 48.57 & 48.24 & 48.57 & 48.24 \\
\hline Hard coal (midload ) & 0 & 0 & 0 & 0 & 0 & 0 & 0 & 0 \\
\hline Lignite (baseload) & 64.29 & 64.26 & 64.29 & 64.34 & 0 & 0 & 0 & 0 \\
\hline Wind & 0 & 0 & 0 & 0 & 121.46 & 122.30 & 121.47 & 122.52 \\
\hline Solar PV & 0 & 0 & 0 & 0 & 88.90 & 89.47 & 88.90 & 89.64 \\
\hline Total & 79.31 & 78.23 & 79.13 & 74.83 & 276.96 & 277.73 & 276.84 & 275.77 \\
\hline \multicolumn{9}{|l|}{ Annual supply costs [€million/year] } \\
\hline Variable costs & 8,655 & 8,637 & 8,656 & 8,654 & 27,830 & 27,571 & 27,830 & 27,542 \\
\hline Fixed costs & 10,045 & 9,972 & 10,038 & 9,843 & 28,489 & 28,603 & 28,485 & 28,552 \\
\hline Capacity market payments & 3,198 & 3,154 & 3,191 & 3,018 & 2,686 & 2,660 & 2,680 & 2,565 \\
\hline Total & 18,700 & 18,609 & 18,694 & 18,497 & 56,319 & 56,174 & 56,314 & 56,094 \\
\hline
\end{tabular}

\section{Appendix B. Welfare gains from RTP with VRE capacity subsidization}

In this section we demonstrate that welfare gains from rising RTP shares also change nonmonotonously with the VRE share if VRE capacity is subsidized ${ }^{38}$ Figure B.5a and

\footnotetext{
${ }^{38}$ To simulate this scenario, we use a modified version of the above model in order to determine endogenously the specific subsidy required to induce a given equilibrium VRE supply share. That is we nest the above MCP model in a "mathematical program with equilibrium constraints" (MPEC) as further explained in Pahle et al. (2016). We also exclude the PRM constraint and thus model a so called "energy-only market".
} 


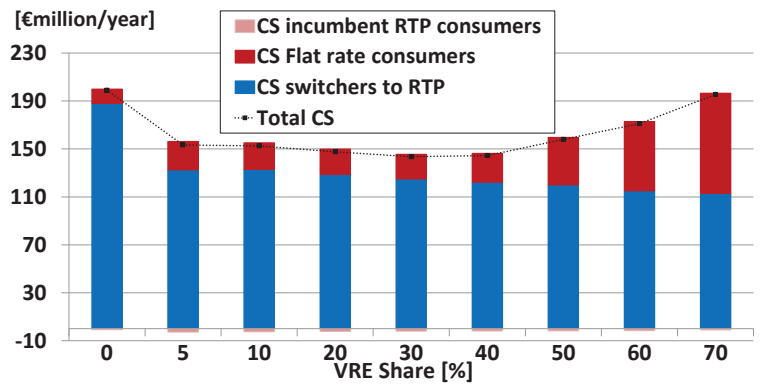

(a) Decomposed annual consumer surplus gains from raising the RTP share from $1 \%$ to $20 \%$ and the VRE share in GEC from $0 \%$ to $70 \%$.

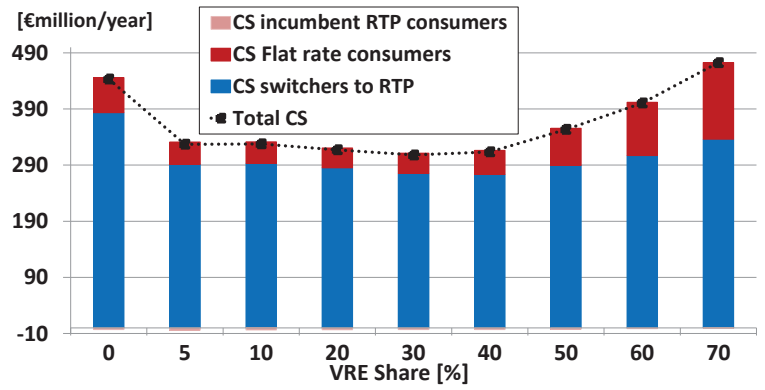

(b) Decomposed annual consumer surplus gains from raising the RTP share from $1 \%$ to $50 \%$ and the VRE share in GEC from $0 \%$ to $70 \%$.

Figure B.5: Annual consumer surplus gains from RTP share increases under VRE capacity subsidization.

B.5b show that up to a VRE share of $40 \%$, TCS gains from raising the RTP share to $20 \%$ or $50 \%$ decrease compared to the levels obtained without VRE supply. From this point onward TCS gains rise again but remain below the level achieved without VRE supply when the RTP share is raised to $20 \%$. When the RTP share is raised to $50 \%$, corresponding TCS gains are lower than without VRE supply unless the VRE share amounts to 70\% (Figure B.5b).

Here, the nonmonotonous change of welfare gains from RTP mainly results from the change in the uniform per unit tax $\tau$ to finance the VRE subsidy. As each consumer pays $\tau$ per consumed unit, this tax constitutes a time-invariant wedge between retail and wholesale electricity prices, which increases with VRE entry. This wedge increases, since wholesale prices equal zero increasingly often with higher VRE entry, whereas the subsidy and accordingly the tax rise simultaneously, since VRE technologies earn less and less short-run profits at the wholesale market (cf. Lamont, 2008). As VRE market profitability declines disproportionately, subsidies to refinance VRE capacity costs have to rise disproportionately with the given VRE target, too (cf. Green and Léautier, 2015). In the equilibria of Figure B.5. $\tau$ rises from $€ 3$ to $€ 73$ per MWh. Simultaneously, $\bar{p}$ drops from $€ 40$ per MWh to around €31 per MWh.

This entails several effects on switching consumers' surplus gains. Flat retail rates increase with the VRE share as $\tau$ rises faster than $\bar{p}$ declines. This would make switching to RTP 


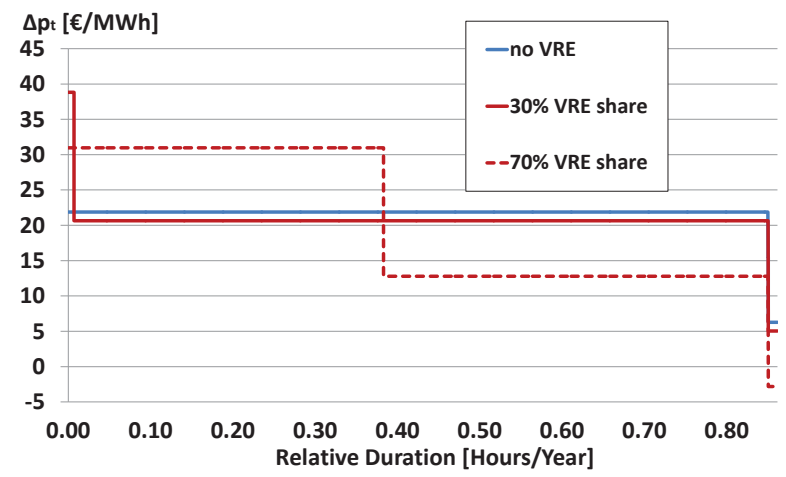

Figure B.6: Positive retail price spreads, i.e. $\bar{p}-p_{t}>0$, at $\alpha=1 \%$ faced by consumers switching to RTP at $0 \%, 30 \%$ and $70 \%$ VRE supply shares in GEC.

in principle more beneficial if hourly RTP rates could drop to the marginal costs of supply. However, this is not the case due to the tax mark up that RTP consumers pay per unit of consumption. Instead, the majority of positive price spreads if switching to RTP, $\triangle p_{t}^{R T P}$, declines at low VRE shares as shown by the solid red curve in Figure B.6. At relatively low VRE shares, VRE set prices relatively infrequently such that real-time retail prices mostly equal the marginal production costs of coal or lignite units plus the tax $\tau$. The corresponding positive price spread for switching consumers therefore equals $\bar{p}-m c_{i}^{N V}$ most of the time, which is lower than without VRE entry, since $\bar{p}$ decreases (slightly) with increasing VRE shares. Hence, comparing the large plateaus of the blue and red solid graphs in Figure B.6 gives that $\bar{p}-m c_{i}^{N V}$ amounts to $€ 22$ per MWh without VRE (blue graph) and $€ 21$ per MWh with a $30 \%$ VRE share in $85 \%$ of the time. When the VRE share equals $70 \%$ in equilibrium, switchers face price drops of $\bar{p}-m c_{i}^{N V}$ only amounting to $€ 15$ per MWh, however, only in about $60 \%$ of the time (dashed red line in Figure B.6). In most of the remaining hours, price spreads rise to $\bar{p}=31 € / M W h$ when VRE supply at zero marginal costs so that wholesale prices drop to zero. Thus, TCS gains from switching start to increase again (blue bars in Figure B.5, at least if the RTP share is raised to $50 \%$.

Interestingly, in contrast to the carbon tax scenario the rise in TCS gains at higher VRE shares is not or only partially due to the change in total surplus gains from switching to RTP. In fact, switching to RTP remains less beneficial than in the market without VRE. Flat rate 
consumers, however, increasingly benefit from a switch to RTP by other consumers (red bars in Figure B.5). The latter results from an increasing drop in the final flat rate $(\bar{p}+\tau)$ when the RTP consumer share rises. When RTP consumers react to low prices, wholesale prices rise during hours where a large part of VRE capacity supplies energy. Thus $\tau$ decreases, since VRE technologies become more profitable and less subsidies are needed to reach a given VRE share. This positive pecuniary externality increases with the VRE share and thus leads to the increasing benefits of flat consumers for given RTP share increases. Simultaneously, $\bar{p}$ declines with VRE entry as explained above, yet not as strong as $\tau$ declines.

\section{Appendix C. Impact of the planning reserve margin on welfare gains from RTP}

Table C.4: Selected welfare results without PRM and with a PRM of 15\% (base case 5\%) under the DICAP and CICAP mechanism for varying VRE shares.

\begin{tabular}{|c|c|c|c|c|c|c|c|}
\hline Scenario & & & $\begin{array}{r}\mathrm{RT} \\
\text { ris }\end{array}$ & $\begin{array}{l}\text { consum } \\
\text { from } 10\end{array}$ & $\begin{array}{l}r \text { share } \\
0 \text { to } 20 \%\end{array}$ & & \\
\hline Market Design & & 10 PRN & & CICAP & DICAP & CICAP & DICAP \\
\hline VRE Share in Gross Consumption [\%] & 0 & 48 & 58 & 0 & 0 & 58 & 58 \\
\hline Annual Consumer Surplus Change [€r & & & & & & & \\
\hline Incumbent RTP Consumers & -0.84 & -2.12 & -1.77 & 0.50 & -0.97 & 0.35 & -2.07 \\
\hline Switchers to RTP & 188.26 & 137.27 & 207.43 & 54.22 & 211.34 & 119.86 & 220.05 \\
\hline Never RTP Consumers & 11.70 & 16.40 & 20.48 & 44.29 & 13.55 & 34.45 & 24.65 \\
\hline Total & 199.10 & 151.55 & 226.14 & 99.01 & 223.92 & 154.66 & 242.63 \\
\hline
\end{tabular}

Table C.4 illustrates that the PRM and thus $p c$ have a negligible quantitative, yet, no qualitative impact on the welfare results found before. Hence, welfare gains from raising the RTP consumer share to $20 \%$ also change nonmonotonously without PRM constraint. If the PRM equals 15\% under DICAP, welfare gains from raising the RTP share from $1 \%$ to $20 \%$ are approximately 11\% higher than without any PRM (energy-only market) and about $4 \%$ higher than in the base case (not shown). Under CICAP, welfare gains from RTP are substantially lower than under DICAP or than in the energy-only market for any given VRE share. This follows the intuition given in 5.3 and is due to the flat capacity price $p c$ that RTP consumers have to pay, too. Switchers to RTP thus face comparatively low price drops such that switching is less beneficial than under DICAP or than in the energy-only market. As above, surplus gains from switching majorly determine the total welfare gains from RTP. 


\section{Appendix D. Impact of higher own-price elasticity}

As explained before and following from comparing the results in Table 2 and Table D.5. total welfare gains from given RTP increases rise in proportion with own-price elasticity $\epsilon$. Again, the corresponding welfare gains still change nonmonotonously with the carbon tax.

Table D.5: Annual consumer surplus changes from increasing RTP under DICAP with higher price elasticity (base case -0.05).

\begin{tabular}{|c|c|c|c|c|c|c|c|c|}
\hline \multirow{2}{*}{$\begin{array}{c}\text { Carbon tax } \tau \\
\text { (VRE share in } \\
\text { GEC ) } \\
\left.\text { [€/tCO } \mathrm{CO}_{2}\right]\end{array}$} & \multirow{2}{*}{$\begin{array}{c}\text { RTP } \\
\text { consumer } \\
\text { share } \\
\alpha\end{array}$} & \multicolumn{4}{|c|}{$\begin{array}{l}\text { Annual consumer surplus } \\
\text { change } \\
{[\in \text { Emillion/year }]}\end{array}$} & \multicolumn{3}{|c|}{$\begin{array}{l}\text { Annual consumer surplus } \\
\text { change per customer } \\
\text { [€/year/customer] }\end{array}$} \\
\hline & & Total & $\begin{array}{c}\text { Incumbent } \\
\text { RTP } \\
\text { Consumers }\end{array}$ & $\begin{array}{c}\text { Flat Rate } \\
\text { Consumers } \\
\epsilon=-0.1\end{array}$ & $\begin{array}{l}\text { Switchers } \\
\text { to RTP }\end{array}$ & $\begin{array}{l}\text { Incumbent } \\
\text { RTP } \\
\text { Consumers }\end{array}$ & $\begin{array}{c}\text { Flat Rate } \\
\text { Consumers }\end{array}$ & $\begin{array}{c}\text { Switchers } \\
\text { to RTP }\end{array}$ \\
\hline $\begin{array}{cl}0 \\
150(48 \%) \\
250(57 \%)\end{array}$ & $\begin{array}{l}20 \% \\
20 \% \\
20 \%\end{array}$ & $\begin{array}{l}396.44 \\
297.31 \\
449.16\end{array}$ & $\begin{array}{l}-4.02 \\
-5.04 \\
-5.07\end{array}$ & $\begin{array}{c}49.85 \\
36.70 \\
46.00 \\
\epsilon=-0.2\end{array}$ & $\begin{array}{l}350.61 \\
265.65 \\
408.24\end{array}$ & $\begin{array}{l}-8.93 \\
-11.21 \\
-11.27\end{array}$ & $\begin{array}{l}1.38 \\
1.02 \\
1.28\end{array}$ & $\begin{array}{l}41.01 \\
31.07 \\
47.75\end{array}$ \\
\hline $\begin{array}{cl} & 0 \\
150 & (48 \%) \\
250 & (57 \%)\end{array}$ & $\begin{array}{l}20 \% \\
20 \% \\
20 \%\end{array}$ & $\begin{array}{l}836.00 \\
593.41 \\
928.44\end{array}$ & $\begin{array}{l}-17.78 \\
-11.29 \\
-12.40\end{array}$ & $\begin{array}{c}218.25 \\
84.65 \\
102.49\end{array}$ & $\begin{array}{l}635.54 \\
520.06 \\
838.35\end{array}$ & $\begin{array}{l}-39.51 \\
-25.10 \\
-27.57\end{array}$ & $\begin{array}{l}6.06 \\
2.35 \\
2.85\end{array}$ & $\begin{array}{l}74.33 \\
60.83 \\
98.05\end{array}$ \\
\hline
\end{tabular}

\section{References}

ACER (2014). Demand Side Flexibility. The Potential Benefits And State Of Play In The European Union. Final Report For ACER. Technical report, Agency for the Cooperation of Energy Regulators (ACER).

Allcott, H. (2011). Rethinking real-time electricity pricing. Resource and Energy Economics 33(4), 820-842.

Allcott, H. (2012). Real-Time Pricing and Electricity Market Design. NYU Working Paper. Ney York University (NYU), 1-53.

Bertsch, J., C. Growitsch, S. Lorenczik, and S. Nagl (2016). Flexibility in Europe's power sector - An additional requirement or an automatic complement? Energy Economics 53, $118-131$.

Borenstein, S. (2005). The Long-Run Effects of Real-Time Electricity Pricing. The Energy Journal 26(3), 93-116.

Borenstein, S. (2012). The Private and Public Economics of Renewable Electricity Generation. Journal of Economic Perspectives 26(1), 67-92. 
Borenstein, S. (2013). Effective and Equitable Adoption of Opt-In Residential Dynamic Electricity Pricing. Review of Industrial Organization 42(2), 127-160.

Borenstein, S. and S. P. Holland (2003). Investment Efficiency in Competitive Electricity Markets With and Without Time-Varying Retail Prices. Working Paper. Center for the Study of Energy Markets (CSEM). University of California Energy Institute, 1-37.

Borenstein, S. and S. P. Holland (2005). On the efficiency of competitive electricity markets with time-invariant retail prices. RAND Journal of Economics 36 (3), 469-493.

Brouwer, A. S., M. Van den Broek, W. Zappa, W. C. Turkenburg, and A. Faaij (2016). Least-cost options for integrating intermittent renewables in low-carbon power systems. Applied Energy 161, 48-74.

Bushnell, J. (2010). Building blocks: Investment in renewable and non-renewable technologies. In B. Modelle, J. Padilla, and R. Schmalensee (Eds.), Harnessing Renewable Energy in Electric Power Systems: Theory, Practice, Policy., Chapter 9, pp. 159-180. RFF Press.

Chao, H. P. (2011). Efficient pricing and investment in electricity markets with intermittent resources. Energy Policy 39(7), 3945-3953.

Connect Energy Economics (2015). Aktionsplan Lastmanagement. Endbericht einer Studie von Connect Energy Economics. Technical report.

Cramton, P., A. Ockenfels, and S. Stoft (2013). Capacity Market Fundamentals. Economics of Energy \&f Environmental Policy 2(2), 1-21.

Cramton, P., A. Ockenfels, and S. Stoft (2015). An International Carbon-Price Commitment Promotes Cooperation. Economics of Energy and Environmental Policy 4(2), 51-64.

Crew, M. A., C. S. Fernando, and P. R. Kleindorfer (1995). The theory of peak-load pricing: A survey. Journal of Regulatory Economics 8(3), 215-248.

DLR, Fraunhofer, IWES, and IfnE (2012). Langfristszenarien und Strategien für den Ausbau der Erneuerbaren Energien in Deutschland bei Berücksichtigung der Entwicklung in Europa und global. Technical report, Federal Ministry for the Environment, Nature Conservation, Building and Nuclear Safety (BMU).

Faruqui, A., Sergici, S. (2010). Houshold Response To Dynamic Pricing Of Electricity - A Survey Of The Experimental Evidence. Journal of Regulatory Economics 38(2), 193-225.

Fell, H. and J. Linn (2013). Renewable electricity policies, heterogeneity, and cost effectiveness. Journal of Environmental Economics and Management 66 (3), 688-707.

Ferris, M. C. and T. S. Munson (2000). Complementarity problems in GAMS and the path solver. Journal of Economic Dynamics and Control 24(2), 165-188.

Gollier, C. and J. Tirole (2015). Negotiating Effective Institutions Against Climate Change. Economics of Energy and Environmental Policy 4 (2), 5-27. 
Green, R. and N. Vasilakos (2011). The long-term impact of wind power on electricity prices and generating capacity. University of Birmingham Economics Discussion Paper, 1-23.

Green, R. J. and T.-O. Léautier (2015, June). Do costs fall faster than revenues ? Dynamics of renewables entry into electricity markets. Working Paper. Toulouse School of Economics (TSE), 1-59.

Hogan, W. W. (2005). On An "Energy Only" Electricity Market Design For Resource Adequacy. Working Paper. Center for Business and Government. Havard University, $1-37$.

Holland, S. P. and E. T. Mansur (2006). The short-run effects of time-varying prices in competitive electricity markets. The Energy Journal 27(4), 127-155.

Icha, P. (2013). Entwicklung der spezifischen Kohlendioxid-Emissionen des deutschen Strommix in den Jahren 1990 bis 2012. Technical report, Umweltbundesamt (UBA).

IEA (2014). World energy outlook 2014. Technical report, International Energy Agency, Paris.

IEA (2016). Re-powering Markets. Market Design and Regulation during the Transition to Low-Carbon Power Systems. Technical report, International Energy Agency, Paris.

Ito, K. (2014). Do consumers respond to marginal or average price? Evidence from nonlinear electricity pricing. American Economic Review 104(2), 537-563.

Jessoe, K. and D. Rapson (2014). Knowledge is (Less) Power: Experimental Evidence from Residential Energy Use. American Economic Review 104(4), 1417-1438.

Joskow, P. and J. Tirole (2007). Reliability and competitive electricity markets. The RAND Journal of Economics 38(1), 60-84.

Kalkuhl, M., O. Edenhofer, and K. Lessmann (2013). Renewable energy subsidies: Secondbest policy or fatal aberration for mitigation? Resource and Energy Economics 35(3), $217-234$.

Lamont, A. D. (2008). Assessing the long-term system value of intermittent electric generation technologies. Energy Economics 30(3), 1208-1231.

Leautier, T. O. (2014). Is mandating "smart meters" smart? Energy Journal 35(4), 135-157.

Mills, A. and R. Wiser (2014). Strategies for Mitigating the Reduction in Economic Value of Variable Generation with Increasing Penetration Levels. Report for the U.S. Department of Energy, 1-57.

Pahle, M., W.-P. Schill, C. Gambardella, and O. Tietjen (2016). Renewable Energy Support, Negative Prices, and Real-time Pricing. The Energy Journal 37(SI3). 
Pfeifenberger, J. P., K. Spees, K. Carden, and N. Wintermantel (2013). Resource Adequacy Requirements: Reliability and Economic Implications. Technical report, The Brattle Group. Prepared for the Federal Energy Regulatory Commission (FERC).

Rutherford, T. F. (1995). Extension of GAMS for complementarity problems arising in applied economic analysis. Journal of Economic Dynamics and Control 19(8), 1299-1324.

Schröder, A., F. Kunz, J. Meiss, R. Mendelvitch, and C. von Hirschhausen (2013). Current and Prospective Costs of Electricity Generation until 2050. Data Documentation 68. DIW Discussion Papers, 1-104.

Weitzman, M. L. (2015). Internalizing the Climate Externality: Can a Uniform Price Commitment Help? Economics of Energy and Environmental Policy 4(2), 37-50. 